Arqueología y Sociedad,

№ 19,2008

\title{
REPRESENTACIONES DE GÉNERO, JERARQUÍA Y OTRAS RELACIONES EN los bordados Paracas Necrópolis
}

Mary Frame*

\section{Resumen}

En este artículo se exploran las categorías y relaciones entre un grupo de figuras interrelacionadas en algunos tejidos bordados de la Necrópolis de Wari Kayan de la Península de Paracas. Primero se discuten las representaciones de las prendas vestidas por las figuras bordadas, y su correspondencia con prendas reales. Las representaciones de prendas revelan el género y posiblemente las categorías de edad entre las figuras, mientras los adornos de oro que llevan sugieren relaciones jerárquicas entre los miembros del grupo. En varios tejidos que exhiben tipos de figuras múltiples, los patrones de repetición de las figuras expresan otras relaciones jerárquicas adicionales, que parecen corresponder con linajes de alto rango. El patrón es un rasgo distintivo de los bordados Paracas Necrópolis, pero a menudo se le estudia separado de la iconografía. Este estudio revela que los patrones de color, simetría y repetición de figuras son aspectos del código gráfico que se reiteran o añaden a las relaciones estructuradas, visibles en la iconografía.

Palabras clave

Bordados de la Necrópolis de Wari Kayan, vestidos de mujer, adornos de oro, iconografía, patrones

\begin{abstract}
This paper explores categories and relationships among a group of inter-related figures on embroidered textiles from the Necropolis of Wari Kayan on the Paracas Peninsula. The depictions of garments worn by the embroidered figures, and their correspondence with actual garments, are discussed first. The garment depictions reveal gender and possibly age categories among the figures, while the golden adornments that they wear suggest hierarchical relationships among the members of the group. Additional hierarchical relationships, which appear to correspond with a high-ranking lineage, are carried in patterns of figure repetition on several textiles that display multiple figure types.

Pattern is a salient feature of the Paracas Necropolis embroideries, but it is often studied in isolation from iconography. This study indicates that patterns of color, symmetry, and figure repetition are aspects of the graphic code that reiterate or add to the structured relationships evident in the iconography.
\end{abstract}

\section{Keywords}

Embroideries from the Necropolis of Wari Kayan; women's dresses; golden adornments; iconography; pattern

\footnotetext{
* Independent Scholar, Vancouver, Canada. Research Associate of the Institute of Andean Studies, Berkeley. Correo electrónico: framem@hotmail.com
} 
En octubre de 1927, el equipo del Museo de Arqueología Peruana hizo un descubrimiento arqueológico trascendental en la península de Paracas. Conducido por Toribio Mejía, bajo la dirección de Julio C. Tello, el equipo exhumó 429 fardos funerarios en la Gran Necrópolis de Wari Kayan (Tello y Mejía 1979), un sitio al que también se le conoce como la Necrópolis de Paracas. Los fardos fueron transportados por etapas a Lima durante los siguientes seis meses, y el personal del museo desplegó un intenso programa para desenfardar, estudiar, preservar y exhibir sus contenidos. Los objetos más espectaculares de los fardos fueron las prendas bordadas, que llegaron a ser famosas en el Perú y en el extranjero, por las publicaciones y exposiciones que hicieron los investigadores principales y sus asistentes. En adición a la arqueología del sitio, las variadas figuras y los provocativos patrones de repetición en las prendas fueron temas de interés para los primeros investigadores ${ }^{1}$.

A pesar de las impresionantes entregas hechas por los estudiosos peruanos en la primera década posterior al descubrimiento, faltan investigar muchas facetas de la imaginería y los patrones. Este estudio enfoca sobre la ropa y los adornos llevados por una figura particular representada en los bordados, y sobre la asociación de esta figura con un grupo de figuras que están vestidas de un modo diferente. La ropa y adornos representados sugieren relaciones variadas entre el grupo de figuras asociadas - relaciones que se reiteran en ciertos tipos de patrones. Para apreciar la diferenciación de la vestimenta representada en la figura central de este estudio, es necesario revisar primero los tipos de prendas que fueron colocados en los fardos funerarios.

\section{TIPOS DE PRENDAS EN LOS FARDOS}

Los primeros diagramas de las prendas bordadas encontradas en los fardos fueron publicados por Rebeca Carrión (1931), quien también proporcionó un rango de medidas para cada tipo de prenda. Ella distinguió entre mantos, llautos (bandas para la cabeza), turbantes y ñañakas (paños largos y cortos), esclavinas, faldas, anakos (vestidos femeninos), unkus (camisas) y waras (pañetes o taparrabos). Esta clasificación ha probado ser muy útil en la mayoría de sus aspectos, excepto por la prenda que identificó como vestido de mujer (anako). Carrión identificó como vestido femenino a una prenda rectangular que tenía bordes bordados en los cuatro lados y lazos cosidos en las cuatro esquinas (1931: 83). Los diferentes ejemplares midieron entre 100 y $160 \mathrm{~cm}$ de largo y un poco menos de ancho $^{2}$. Esta prenda, que Tello y Mejía identificaron como un mantón o lliclla (1979: Figura 128), se parece a una wara (véase Frame 2007b: 68-70 y Figura 9). Asimismo, es similar en su construcción a las waras llanas Nasca Temprano exhumadas en Cahuachi, que también tienen cuatro lazos en las esquinas (O’Neale 1937: 191 y Lámina XXXIVa; Frame 2005: Figura 20).

Aunque las prendas masculinas son más numerosas, hay algunas prendas femeninas incluidas en los fardos. Un tipo de vestido femenino, que no tiene lazos añadidos en las esquinas, ya ha sido identificado (Aponte s. f.). Adicionalmente, en los bordados están representados varios tipos de vestidos femeninos (Frame 2007b: Figuras 7 y 8 ; Frame s. f. ${ }^{3}$ ). Un tipo, que será discutido en detalle en este artículo, se sostenía con tupus (alfileres) por encima de los hombros, mientras los otros no. Los tipos de vestidos re-

1 Carrión 1931, 1949; Fester y Cruellas 1934; Tello 1929; Yacovleff 1932a, 1932b, 1933; Yacovleff y Herrera 1934; Yacovleff y Muelle 1934.

2 Los fardos 319 y 253 tienen un número de prendas denominadas anakos por Carrión (1931:83). Los fardos 38, 89, 290, 310, 378 y 451 también tienen ejemplares. Aunque esta lista no es exhaustiva, muestra que ese tipo de prenda está distribuido entre los fardos que Paul (1990a: Tabla 5.2) ubicó en las últimas fases de su seriación.

3 Una figura de estilo silueta que viste un vestido femenino de bandas horizontales, diferente de los otros dos tipos de vestidos representados, aparece en una esclavina del fardo 420 de la Necrópolis de Paracas (420-3, RT 
presentados que han sido identificados hasta ahora comparten algunos rasgos con los vestidos femeninos Nasca Temprano exhumados en Cahuachi (Frame 2005). Los vestidos femeninos de Cahuachi enfatizan los bordes horizontales decorativos, y sus aberturas para la cabeza y los brazos están orientadas horizontalmente. La orientación horizontal de las aberturas es un rasgo técnico que concuerda con la generalización de Desrosiers sobre las prendas femeninas usadas en la costa, en todos los periodos (1992). Carrión también refiere a las ñañakas o turbantes que pudieron haber sido usados por mujeres. Ambos se hacen con telas delicadas, como gasas, pero la ñañaka es más cuadrada que el turbante rectangular (Carrión 1931: 84-85) y, a veces, envolvía una peluca. Se ha informado de tejidos cuadrangulares con la misma delicada textura en Cahuachi, donde fueron descubiertos en un depósito de prendas femeninas (Frame 2005: Figuras 15-18 y Láminas 13-14). Muy probablemente el turbante rectangular fue usado por ambos sexos, ya que las representaciones bordadas muestras a figuras masculinas y femeninas llevándolo. Los mantos rectangulares también pueden haber sido usados alrededor de los hombros por individuos de ambos sexos, y aquellos de menores dimensiones pueden haber sido chales femeninos. En los fardos se ha en- contrado un pequeño número de esclavinas con aberturas horizontales en el cuello, y algunas de ellas deben haber sido prendas femeninas, si la generalización de Desrosiers es correcta ${ }^{4}$.

La mayoría de tipos de prendas en los fardos funerarios parece ser masculina (Tello y Mejía 1979: Figura 126). En los fardos están presentes varios tipos de waras. Las waras rectangulares tienen dos o cuatro lazos, un rasgo que sugiere que los dos tipos fueron llevados en formas marcadamente diferentes (Frame 2007b: 68-70, Figuras 9 y 11). Las prendas triangulares con dos lazos también han sido identificadas como waras (Carrión 1931: Figura 20), aunque algunas representaciones sugieren que ellas fueron llevadas sobre las caderas, por encima de las waras (De Lavalle y Lang 1983: 84-85). Las túnicas o esclavinas que tienen aberturas verticales en el cuello también son prendas masculinas, presumiblemente. La abertura vertical en el cuello es un rasgo de las prendas masculinas virtualmente en casi todos los estilos (Desrosiers 1992) ${ }^{5}$. Este rasgo se puede utilizar para identificar el género de las prendas que aparecen formando juegos. Las túnicas o esclavinas con aberturas verticales en el cuello a veces hacen juego con faldas y mantos grandes, una indicación que los segundos también son prendas masculinas. La mayoría de los juegos tienen dos o tres prendas,

2999), y sobre un fragmento de borde de un fardo de Arena Blanca (Iriarte 2004, Figura 13, arriba). Delia Aponte reconoció, independientemente, la figura del poncho como mujer, a partir de las bandas horizontales de la prenda (comunicación personal, 23 de abril de 2008). Recientemente he localizado una prenda de bandas horizontales que tiene una estrecha correspondencia visual con los vestidos representados mencionados aquí. El tamaño y la construcción respaldan su identificación como vestido femenino.

En cuanto a los especímenes del Museo Nacional de Arqueología, Antropología e Historia del Perú, he registrado el número de fardo primero, seguido por el número de espécimen. También he anotado los números del Registro Textil (RT) cuando ha sido posible. Los números del RT se utilizan en el catálogo en línea (http://textiles.perucultural.org.pe/paracas), donde se pueden ver las fotografías de varios tejidos.

4 Tello y Mejía 1979: Figura 128: 3, 4; Carrión 1931: Figura 17a, b, fardo 319-30 y 319-69. He identificado otros ejemplares en los fardos 94 (94-45, MNAAH RT 3170), 38 (38-3, MNAAH RT 2692) y 319 (319-23, MNAAH RT 1264). Un tipo de prenda con una abertura horizontal para la cabeza, un tabardo de cuero, parece ser una prenda masculina, ya que la abertura horizontal para la cabeza (Desrosiers 1992) podría no ser un indicador enteramente confiable para identificar las prendas femeninas de Paracas Necrópolis.

5 Para excepciones a la generalización de Desrosiers, véase Ulloa (1981: 112), Clark (1990: Figuras 13, 14), Dransart (1999: 130-137) y la nota 4. 
pero en casos raros pueden estar compuestos por cuatro prendas. Los juegos comprenden algunas de las siguientes prendas: un manto, un turbante (paño largo) o llauto, una falda o wara y un unku (camisa) o esclavina. Los juegos de prendas femeninas aún no han sido identificados.

Carrión se pregunta justificadamente si las prendas de los fardos grandes y medianos fueron usadas alguna vez por los seres humanos (1931: 14-15). Sus tablas ilustran un amplio rango de tallas entre las prendas individuales. Aunque las prendas concuerdan con las proporciones humanas, sus dimensiones no corresponden al tamaño del individuo con el que fueron enterradas, y en el mismo fardo a menudo se encuentran varios tamaños de la misma prenda. Muy pocas prendas muestran señales de uso, como desgastes en la base de las aberturas del cuello o pliegues cerca de los tirantes de la cintura. Algunos mantos colocados en las capas más externas de los fardos están en condiciones casi prístinas. Otra indicación de que las prendas no fueron hechas para el uso de personas vivas es que el bordado está inconcluso, o aún sin comenzar, en un número significativo de especímenes. La desigual distribución de los tipos de prendas en los diferentes fardos también sugiere que las prendas bordadas no formaron parte del guardarropa del vivo. Carrión cita suficientes argumentos para sospechar que las prendas no fueron hechas para el uso en vida de los hombres enterrados en los fardos más grandes ${ }^{6}$.

Una hipótesis alternativa sería que las prendas bordadas fueron hechas para el cadáver, "como señales de su nuevo estatus como difun- to" (Dwyer y Dwyer 1973: 160). Como ofrendas usadas en un ritual mortuorio, las diferencias en el tamaño y la distribución de las prendas podrían haber comunicado ideas equivalentes al estatus o la edad, por ejemplo, dentro del contexto de creencias concernientes a la vida después de la muerte del enterrado (Frame 1995; 2001). Los rasgos de las prendas que transmitieron distinciones sociales y biológicas durante la vida, también pueden haber portado creencias sobre las distinciones sociales y biológicas entre los mismos ancestros.

\section{EL FARDO 382}

El fardo 382 contuvo un juego de tres prendas que repiten una figura bordada cuya inusual vestimenta es el centro de este artículo (Figura 1A-C). La prenda representada aparece tantas veces en otros fardos que se le puede considerar como parte de un repertorio estándar de prendas. La prenda tiene varios rasgos -incluso los pares de tupus que se proyectan sobre los hombros- que indican que se trata de un vestido femenino.

El fardo $382^{7}$ estuvo en el primer grupo de diez fardos que se abrió en Lima y que fue publicado por Carrión (1931: 13-17, 39-52). Ella resumió los contenidos de los diez fardos y comparó las dimensiones de los especímenes en listas y diagramas. También informó que el fardo 382 contenía una gran cantidad de prendas finamente bordadas (mantos, faldas, turbantes, llautos y esclavinas), además de hondas, abanicos, discos de oro, varas, prendas en miniatura, una peluca y paños llanos envolventes ${ }^{8}$. Los te-

6 Paul asume la posición de que las prendas en los fardos eran artículos del guardarropa personal del difunto (p. e. 1990a, 1990b).

7 Recientes investigaciones en los archivos (Ann Peters, comunicación personal, marzo de 2008) han revelado que el fardo denominado 382 en las publicaciones de Tello y sus asistentes, era realmente el fardo 12, un fardo de categoría principal del Núcleo Funerario "A" (véase Tello y Mejía 1979: Figura 86, para la ubicación del fardo 12).

8 Una lista completa del contenido del fardo 382 se encuentra en el Archivo Tello del Museo de Arqueología y Antropología del Centro Cultural de San Marcos (III/P18/F1), y en el Archivo Tello del Museo Nacional de Arqueología, Antropología e Historia del Perú (Número 180, Cuadernillo 39). Agradezco a ambas instituciones por permitirme el acceso a esta información. 


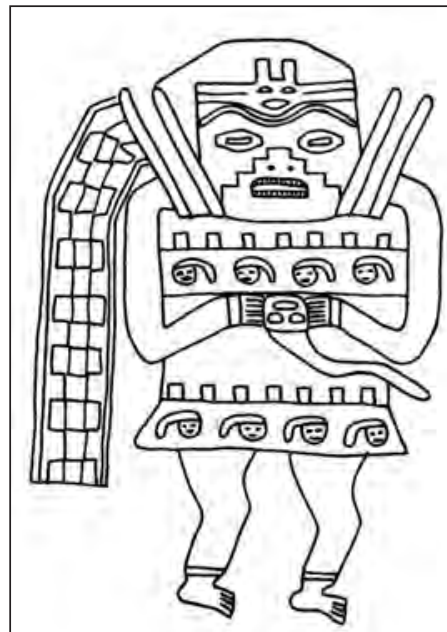

A

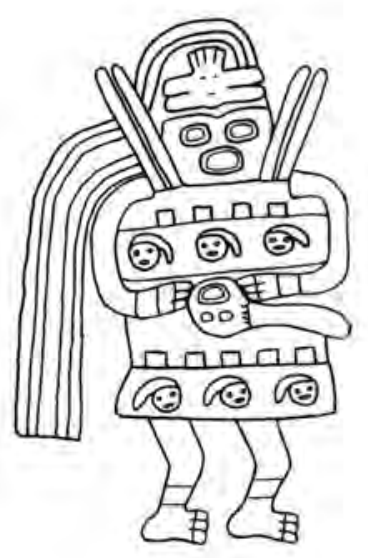

B

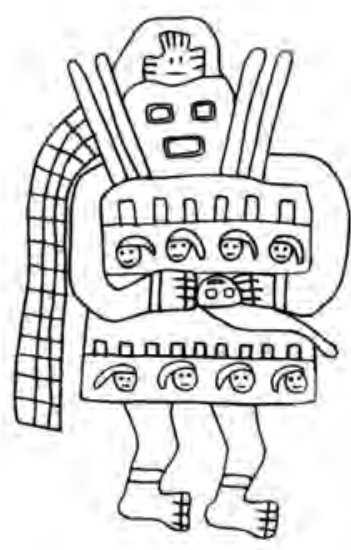

C

Figura 1. Las figuras bordadas representadas en tres tejidos del fardo 382 visten una prenda que puede ser identificada como vestido femenino: tiene dos bordes horizontales y está sujeta a la altura de los hombros con dos pares de tupus. A. Manto 382-7 (MNAAH RT 1443). B. Esclavina 382-43 (MNAAH RT 2819). C. Falda 382-45 (MNAAH RT 2763).

jidos bordados fueron colocados alrededor del cuerpo en cuatro capas, separadas por capas de paños llanos envolventes. La alternancia de capas de tejidos decorados con otras de tejidos llanos es una configuración estándar encontrada en otros fardos que han sido abiertos (Bennett 1938; Tello y Mejía 1979; Paul 1990a). En la capa más externa, alrededor del paquete cónico, fueron envueltos seis mantos bordados. Una acuarela (Figura 2) muestra el cuarto manto fino (382-7, MNAAH RT 1443) in situ, antes de ser removido del fardo 382. Las figuras bordadas que serán discutidas aquí se repiten en los bordes en forma de $\mathrm{C}$ y en el campo central de este manto (Figuras 2 y $3 \mathrm{~A}$ ), y sobre los bordes de una esclavina $(382-43)$ y una falda $(382-45)$ que le hacen juego (Figuras 3B y C) ${ }^{9}$. La esclavina y la falda que hacen juego fueron colocadas en la segunda capa de tejidos bordados.

El manto, la esclavina y la falda tienen bordes bordados púrpura, un tejido de base teñido en color salmón, y muestran versiones de la misma figura (Figura 1A-C). Claramente, las tres prendas fueron hechas a juego. La abertura vertical del cuello de la esclavina, una señal de prenda masculina, indica que este es un conjunto de prendas masculino. El cadáver del fardo 382 también era de varón, ya que se le ha descrito con bigote y barba ${ }^{10}$. Las figuras bordadas en el juego de prendas, sin embargo, pueden ser identificadas como femeninas por las prendas que visten.

\section{DiSTINCIÓN DEL GÉNERO DE LAS FIGURAS BORDADAS}

Las representaciones de las figuras vestidas en los tejidos bordados transmiten informa-

9 El manto, o detalles de él, se han publicado varias veces (De Lavalle y Lang 1977: 58; Mason 1978: Plate 49; Kauffmann Doig 1999: Lámina 36), donde las figuras se han referido como "motivos demoniacos" o "personajes, posiblemente guerreros". Las figuras también han sido publicadas en fotografías o dibujos (Carrión 1931: Figura 12j; Paul 1990a: Figura 5.6; 1990b: Figura 8), pero no fueron identificadas como mujeres.

10 Archivo Tello del Museo Nacional de Arqueología, Antropología e Historia del Perú (Número 180, Cuadernillo 39, p. 9). 


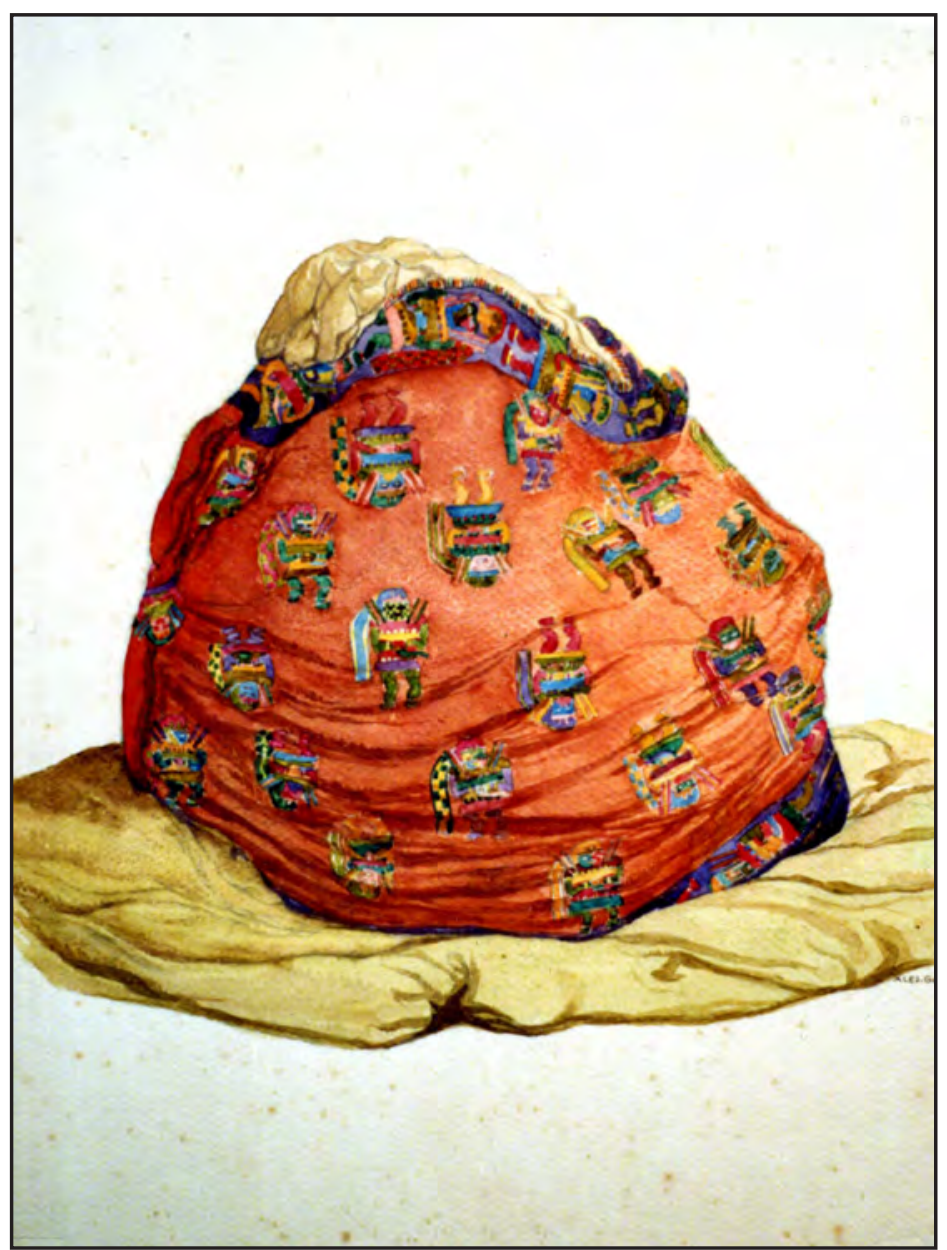

Figura 2. Acuarela del manto 382-7 antes de ser removido del fardo, pintada por Alejandro González. Archivo Tello del Museo de Arqueología y Antropología del Centro Cultural de la Universidad Nacional Mayor de San Marcos, III/P18/ F3/FIV.

ción generalizada sobre cómo se usaban algunas prendas y por quiénes. Los rasgos de las prendas representadas se pueden utilizar para identificar el tipo de vestimenta y, por lo tanto, a la figura como hombre o mujer. Las figuras que visten waras, usualmente con una túnica corta con o sin mangas con flecos, se pueden asumir como varones. Las figuras que usan faldas cortas también se pueden asumir como varones, porque las faldas forman parte de los conjuntos que hacen juego con las esclavinas o túnicas. Las otras figuras bordadas que visten túnicas más largas y que no muestran una wara son más variadas, y no son necesariamente varones, aunque muchas de ellas lo son. La representación de mangas con flecos en túnicas largas, similares a aquellas túnicas masculinas Nasca (Rowe 1991: Figuras $15-17$ y 19 ), se puede utilizar para identificar a algunas figuras como varones.

Las figuras en el juego de prendas del fardo 382 visten un tipo de prenda diferente de las prendas masculinas. Un rasgo significativo es la presencia de bordes horizontales a través del pecho y en el orillo más bajo (Figura 1A-C). Una fila de cuadrados pequeños, representada a lo largo del orillo superior de ambos bordes, es otro atributo que ayuda a confirmar la identificación de la prenda, lo que ilustraré más adelante. En la mayoría de las representaciones los hombros están descubiertos. La figura viste un turbante largo que cae a un lado y una diadema alada sobre la frente, que corresponde a un tipo de adorno de oro martillado que se ha encontrado en varios fardos (Tello y Mejía 1979: 460-69). La figura sostiene frente a su torso una cabeza cercenada, de cabello largo. El rasgo más destacado es el par de objetos, tipo varas, que sobresalen de los hombros. Ahora se puede identificar a la prenda representada como un vestido femenino sostenido sobre los hombros con dos pares de tupus. Las comparaciones con vestidos reales de este periodo de tiempo aclaran los parecidos. 
Un depósito de ropa de mujeres, exhumado por Giuseppe Orefici en 1998 en Cahuachi (Frame 2005), incluyó vestidos que contienen rasgos que se corresponden con algunos de aquellos de las prendas representadas ${ }^{11}$. El borde horizontal que cruza el pecho en las representaciones de los vestidos corresponde con el orillo más bajo de la capa doblada de tela que cae sobre el corpiño (Figura 4). Entre los veinticinco vestidos o fragmentos de vestidos exhumados en $\mathrm{Ca}$ huachi, todos los pedazos que incluyen la sección del corpiño tienen este rasgo. El orillo más bajo de la capa doblada a veces tiene una banda bordada o una banda llana con flecos que atraviesa el pecho horizontalmente. Sobre el corpiño de algunos vestidos, pequeñas lengüetas cuadradas, hechas con aguja en tejido anillado sobre un elemento base, unen la banda bordada con el orillo de la capa doblada de tela. Las lengüetas anilladas y los bordes de los vestidos reales (Figura 4; Frame 2005: Plate 1) tienen una estrecha correspondencia visual con la banda bordada horizontal y la fila de cuadrados pequeños sobre el corpiño de los vestidos representados (Figura 1A-C). Las aberturas

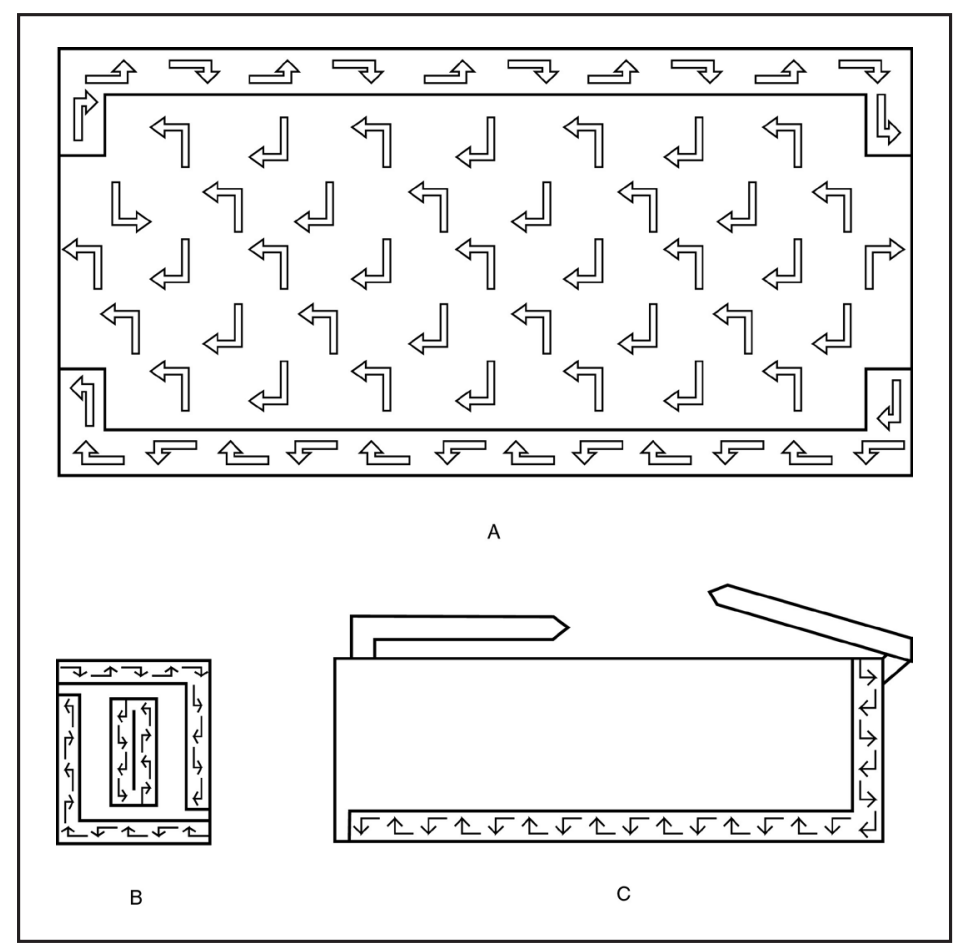

Figura 3. Diagramas a escala de las prendas a juego del fardo 382, con la orientación de las figuras que llevan vestidos femeninos. A. Manto 382-7 (MNAAH RT 1443), $277 \times 134 \mathrm{~cm}$. B. Esclavina 382-43 (MNAAH RT 2819), $55 \times 41 \mathrm{~cm}$. C. Falda 382-45 (MNAAH RT 2763), $173 \times 56 \mathrm{~cm}$.

para la cabeza y los brazos, situadas en el borde superior de la prenda, están orientadas horizontalmente.

El par de proyecciones, como varas, que surgen de los hombros de las figuras, representan alfileres sobre los hombros, o tupus, como se les llamaba en los tiempos Inka. Los alfileres, colocados sobre los hombros, eran usados con las puntas hacia arriba, de modo que las puntas de los alfileres se podrían haber proyectado sobre la línea del hombro tal como aparecen en las representaciones de los vestidos femeninos. Al usar alfileres a la altura de los hombros para sujetar el frente con el fondo del vestido, resulta una prenda que deja los hombros desnudos, un rasgo que se corresponde con las representaciones de las figuras (Figura 1A-C). Los vestidos de Cahuachi difieren en este aspecto porque tienen las

11 Los vestidos de Cahuachi tienen un promedio de 120 a $125 \mathrm{~cm}$ de largo. Una réplica de un vestido de Cahuachi llegó hasta el tobillo de una mujer peruana (Frame 2005: Figura 9). Dos vestidos del conjunto son más pequeños, apropiados en tamaño para niñas. Uno fue agrandado, pero solo hasta los $111 \mathrm{~cm}$ de largo (ibíd. 2005: Figura 5). El otro fue rehecho a partir de un panel de un vestido de tamaño normal, y mide $76 \mathrm{~cm}$ de largo (ibíd. 2005: Plate 12). 


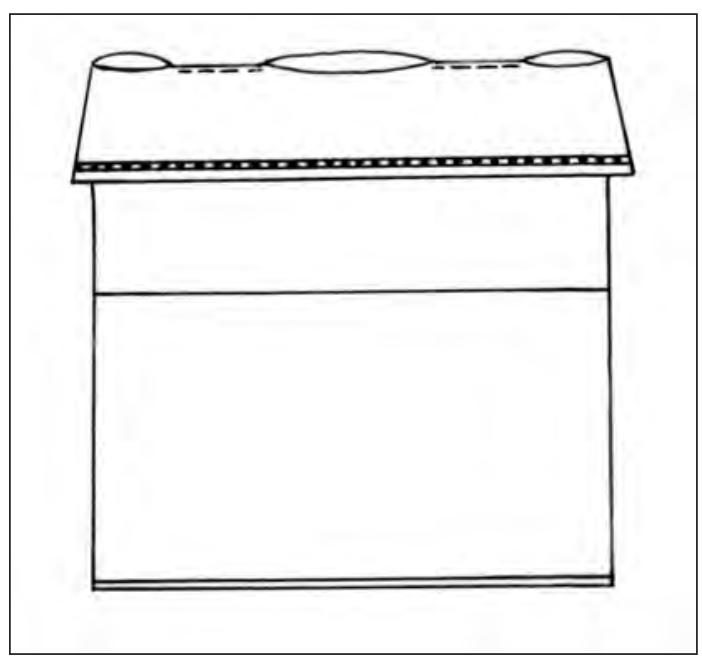

Figura 4. Diagrama de un vestido femenino exhumado en Cahuachi por el Proyecto Nasca en 1998 (Sector Y16/ T1/no. 2). Los vestidos reales tienen una franja de tela doblada sobre el pecho, un rasgo que concuerda con las prendas representadas en la figura 1A-C. 120 $x 122 \mathrm{~cm}$.

junturas cosidas en los hombros, y podrían no haber sido llevados con alfileres. Los vestidos de Cahuachi se corresponden más completamente con el otro estilo de vestidos representados en los bordados, que no muestran alfileres a la altura de los hombros (Frame 2007b: Figura 7). El segundo tipo de vestidos representados tiene bordes en el dobladillo y/o en el corpiño. Los dos tipos de vestidos parecen haber sido bastante similares en su construcción, con la diferencia principal en la manera en la cual fueron sujetados en los hombros. Las diferencias entre los vestidos, reales y representadas, parecen indicar que varias entidades políticas con diferentes tradiciones de vestido contribuyeron con prendas para los rituales mortuorios de Paracas Necrópolis (Frame 1995:15; 2001: 89; 2007b).

Las fuentes etnohistóricas indican que las mujeres andinas que usaban alfileres para sujetar sus vestidos generalmente usaban un único alfiler sobre cada hombro, más que pares de alfileres como se representa en las figuras bordadas. Aparentemente, la práctica de usar pares de alfileres era rara. La descripción de Juan de
Betanzos sobre un momento en el que se usaban pares de alfileres, durante el período Inka, puede sugerir por qué (1996 [1576]: 78). Betanzos describe cómo la novia del Inka Yupanque usó un vestido finamente tejido, sujetado con cuatro alfileres de oro, cada uno de dos palmos de largo, cuando fue presentada al Inka para que sea su esposa, poco después que este fuera coronado. Difícilmente se puede imaginar un momento más significativo o estatus social más elevado. Los pares de alfileres largos sobre los hombros de las figuras bordadas puede indicar el alto estatus de las mujeres representadas.

La corta longitud de los vestidos representados en los bordados ha confundido a algunos investigadores, que han asumido que son prendas masculinas, como túnicas (Paul 1990a: Figura 5.6) o tabardos de cuero (Rowe 1991: 103 y Notas 14-15). Sin embargo, los bordes horizontales que cruzan el pecho y las proyecciones tipo varas que salen de los hombros dejan pocas dudas sobre el hecho que se trata de la representación de un vestido con alfileres a la altura de los hombros. Los vestidos femeninos representados en los bordes del famoso tejido Nasca del Museo de Brooklyn varían considerablemente en longitud: hasta el tobillo, a media pantorrilla o a la rodilla (Figura 5A-C). No muestran los alfileres sobre los hombros, y en este aspecto se parecen a los vestidos reales de Cahuachi. Las diferencias en las longitudes de los vestidos representados podrían haber servido para indicar una idea, quizás la edad. Una figura que usa un vestido largo está encorvada como si fuera muy anciana (Figura 5A). Quizás los vestidos más cortos (Figuras 1A-C, 5B-C) correspondan a una expresión equivalente a la juventud en el código visual.

Las figuras (Figura 1A-C) usan un turbante colgante en conjunto con la prenda identificada como vestido femenino. Los turbantes de las figuras bordadas tienen una forma similar a la de los tejidos estrechos y largos de textura tipo 


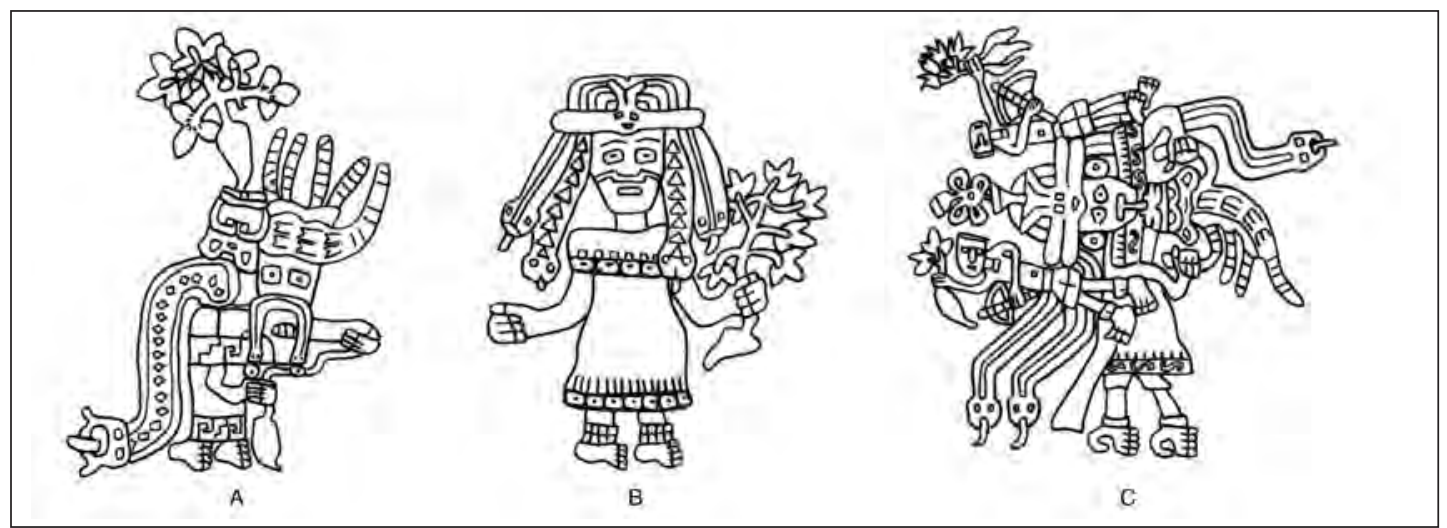

Figura 5. Tres figuras de un tejido Nasca (TBM 38.121) llevan vestidos de diferentes longitudes. Las diferencias en el largo podrían corresponder a diferencias en la edad. Tomado de Martin 1991, figuras 55, 48 y 13.

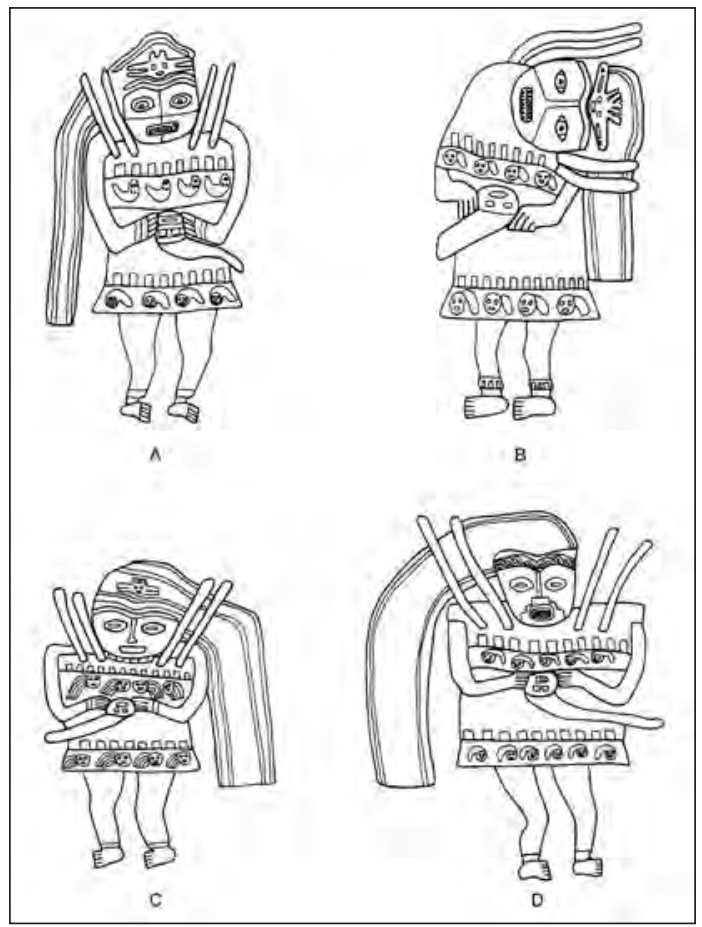

Figura 6. En otros fardos recuperados en Paracas Necrópolis fueron incluidas figuras que llevan vestidos $y$ turbantes similares a aquellos de las figuras en los tejidos del fardo 382. A. Manto 157-21a (MNAAH RT 2539). B. Manto 188-8 (AMNH 41.2/8869). C. Manto 217-10 (MNAAH RT 25589). D. manto 451. 5 (MNAAH RT 3044). gasa que Carrión denominó turbantes (1931: 84-85). En las representaciones bordadas, hombres y mujeres visten turbantes, pero entre ellos podría haber ligeras diferencias que aún no han sido definidas. En los bordados se representan algunos tipos de adornos usados por ambos sexos, como las diademas y los llautos.

Las figuras que llevan vestidos con pares de alfileres aparecen en los tejidos bordados de al menos otros cinco fardos de la Necrópolis de Wari Kayan (Figura 6). Las prendas representadas tienen todas un borde horizontal a través del pecho y un borde paralelo en el extremo inferior, así como pares de alfileres sobre cada hombro (Figura 6A-D). Todas las figuras visten un turbante con colgante y tres de ellas llevan diademas. Los tejidos en los fardos $157^{12}$, 188, 217, 421 y 451, que exhiben estas figuras, no tienen prendas en juegos, a diferencia del trío del fardo 382.

Las figuras bordadas que pueden ser identificadas como mujeres llevan vestidos de al menos dos tipos: aquellos que muestran alfileres sobre los hombros (Figura 1A-C y 6A-D) y aquellos que no (Frame 2007b: Figura 7). Ambos tipos tienen bordes horizontales en el corpiño y a ve-

12 La asociación del tejido RT 2539 con el espécimen 21a del fardo 157 ha sido puesta en duda por una reciente investigación de las fuentes que documentan la apertura del fardo 157 (Delia Aponte, comunicación personal, febrero de 2008). 
ces un segundo borde a través del pecho. Los bordes a menudo muestran una línea de cuadrados a lo largo del extremo superior. El segundo tipo de vestidos representados se corresponde más plenamente con los vestidos de Cahuachi, y probablemente se origina en la tradición Nasca. Las figuras de estilo Nasca que llevan vestidos tienen algunos tipos de ornamentos y accesorios diferentes de las figuras centrales en este estudio.

\section{¿Figuras humanas O DE ANCESTROs?}

Las figuras bordadas son anatómicamente consistentes con los seres humanos y visten ropa de mujeres, pero isignifica que son representaciones realistas de mujeres? Varios rasgos sugieren que son figuras míticas, posiblemente figuras de ancestros. La boca de la mayoría de las figuras está levemente abierta, un rasgo asociado a menudo con los muertos en el arte andino. La forma del ojo, redondeada y sin pupila en la mayoría de los casos, también podría sugerir que la figura representada está muerta (Figura 1A-C; Figura 6A-D). Una figura que usa un vestido femenino (188-8, Figura 6B) se muestra en una postura anormal, doblada hacia atrás.

La postura doblada hacia atrás está particularmente asociada con un grupo de figuras masculinas que visten falda y llevan abanico y bastón (Lavalle y Lang 1977: 56-57). En un detallado estudio sobre la figura masculina doblada hacia atrás en los bordados Necrópolis (Frame 2001: Figura 4.3a, b), he sostenido que la figura está representando un acto mítico de auto-sacrificio. La figura parece estar sacando un abanico en forma de corazón de un agujero en su pecho hinchado, y luego sostiene el abanico/corazón hacia arriba en representaciones alternantes. Aparentemente, algunas de las figuras feme- ninas (Figuras 1A-B y 6D) también tienen un agujero en el torso, debido a que el área entre el brazo y el cabello de la cabeza cercenada no está bordada con el mismo color del vestido que llevan. El color del paño del fondo se introduce en esta área, lo que implica que hay un agujero en el cuerpo. Las mujeres pueden haber sido representadas como sacando la cabeza cercenada de sus torsos, más que simplemente sosteniendo a la cabeza. Este acto anormal es otra indicación de que las figuras representadas son míticas.

Las representaciones de ancestros míticos bien pueden haber reflejado el código de vestido de los humanos en cuestiones tales como las distinciones de género y edad, especialmente si el dominio de los ancestros se pensaba como una imagen reflejada del reino terrenal. Ciertos atributos y acciones implícitas de las figuras bordadas sugieren que no fueron hechas para representar a seres humanos vivos. Sin embargo, podrían representar antepasados míticos de los seres humanos, que no estuvieron constreñidos por imposibles fisiológicos.

Existen fragmentos de tejidos adicionales con la misma figura en las colecciones de varios museos ${ }^{13}$. Dos prendas completas en colecciones de museos, que serán discutidas en mayor detalle, muestran una figura que usa un vestido, en compañía de tres o siete figuras adicionales que usan todas ropas diferentes.

\section{¿UNA AGRUPACIÓN DE FIGURAS DE ANCESTROS INTERRELACIONADOS?}

La figura bordada que lleva el vestido con alfileres a la altura de los hombros (Figuras 1AC; 6A-D) también aparece en una falda y en un manto inusuales que no fueron exhumados en 192714. La falda (Stone-Miller 1992: Plate 7) y el manto (Lumbreras 1976: Figura 102) son

13 Los fragmentos del borde del manto que muestran una figura vestida de modo similar, en postura erguida, son los TM 91.101 (Bird 1954: Plate 8, derecha) y MMA 33.149.87. Un fragmento de borde más estrecho muestra la variante con la cabeza inclinada hacia atrás (EMB VA 63319, Eisleb 1975: Figura 179).

14 La falda (MFAB 21.2563) fue comprada por Denman Ross, el director del Museum of Fine Arts de Boston, alrededor de 1915 e ingresada en 1921 (Daggett 1991: 36-38), antes del descubrimiento de la Necrópolis de Wari 


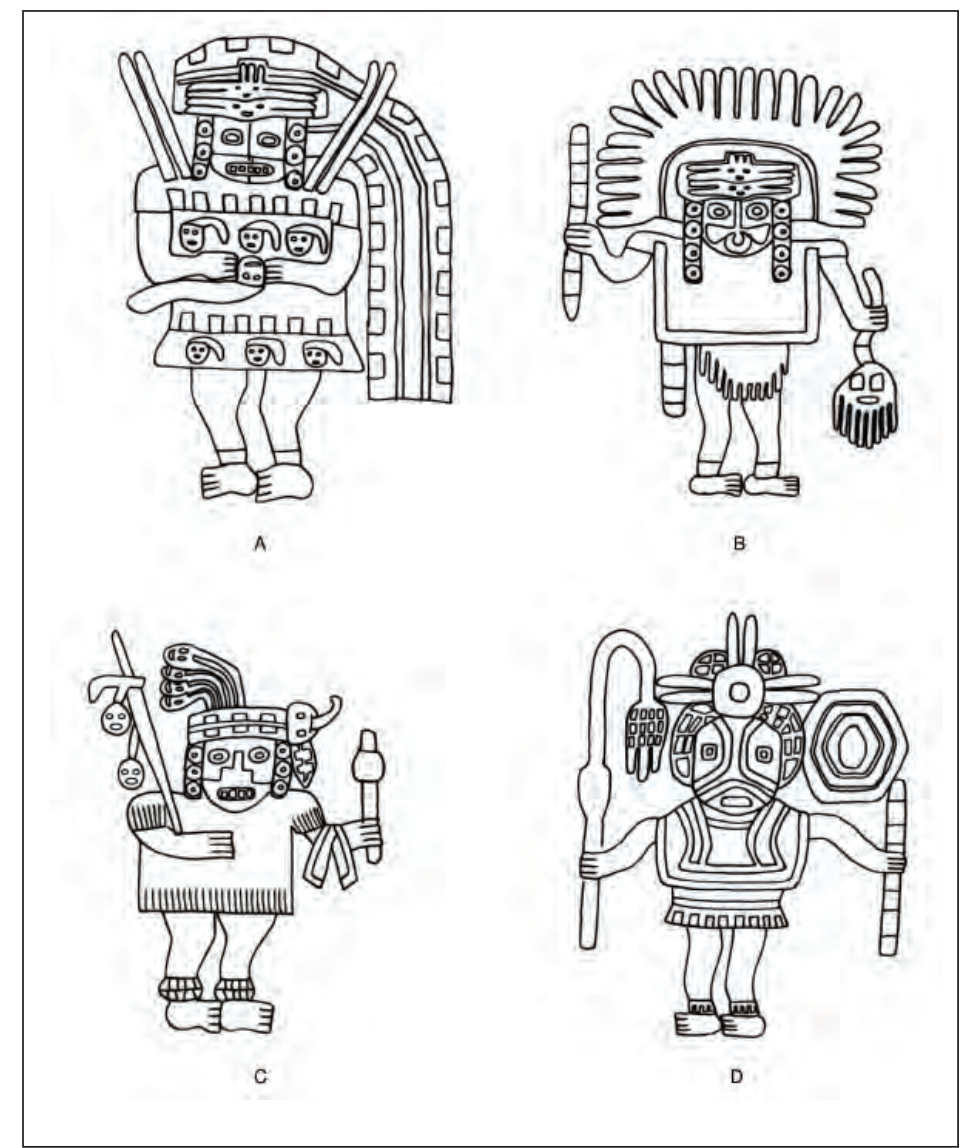

Figura 7. Cuatro figuras se repiten regularmente sobre el campo y los bordes de una falda bordada (MFAB 21.2563). Solo una figura lleva un vestido femenino; las otras, prendas masculinas. A. Figura que lleva un vestido femenino. B. Figura que viste túnica, wara y tocado en forma de media luna. C. Figura que viste una túnica larga con mangas con flecos. D. Figura que viste túnica y falda.

inusuales porque en ellos se repiten cuatro y ocho figuras respectivamente, en vez de una sola figura, como en la mayoría de las prendas bordadas de Paracas Necrópolis.

El grupo de cuatro figuras de la falda negra (Figura 7A-D) abarca la mitad del grupo de ocho figuras del manto blanco. En estas dos prendas la figura con vestido suscita una visión de contexto más iconográfico que arqueológico. La figura con vestido está acompañada por figuras que visten ropas masculinas, de acuerdo a los rasgos ya descritos. En el nivel más básico, el contexto iconográfico muestra una distinción de géneros dentro de los grupos de cuatro y ocho figuras. A continuación, exploraremos las relaciones adicionales sugeridas por los adornos llevados por las diferentes figuras, y por las repeticiones de los patrones sobre ellas.

\section{La falda negra}

Un rasgo sobresaliente de los bordados Paracas Necrópolis es el patrón de repetición de una única figura en diferentes colores y orientaciones. La falda negra, que tiene bordes amarillos, muestra otra faceta del patrón en la alternancia regular de diferentes figuras (Figura 8A). Las cuatro figuras (Figura 7A-D) se repiten en una secuencia regular, lineal, sobre el borde con forma de L, orientándose alternativamente hacia la derecha y la izquierda. En el campo de la falda, las cuatro figuras se repiten sobre un ajedrezado. El efecto visual más fuerte está sobre las diagonales que corren desde arriba a la izquierda hacia abajo a la derecha, donde las dos figuras mayores están emparejadas y las dos menores también. La figura con vestido y la figura que usa un tocado emplumado largo (Figura 8A:

Kayan. El manto, que está en la colección del Museo de Arqueología de la Universidad Nacional Mayor de San Marcos, también puede haber sido ingresado alrededor de 1919 ó 1920, cuando Tello le donó 58 tejidos Paracas y una momia Paracas (Tello 1959: 43; Daggett 1991: 38). Algunas figuras del manto fueron reproducidas por Carrión (1931: Figuras 12e, f y h). 
A, B; también Figura 7A, B) se alternan sobre una diagonal, y las dos figuras menores (Figura 8A: C, D; también Figura 7C, D) se alternan sobre la diagonales adyacentes. El efecto visual sobre las diagonales está resaltado porque cada figura está coloreada en una forma distintiva. El patrón de color y el patrón de la figura coinciden en la falda negra (Figura 8A), aunque no coinciden en el manto blanco. El patrón de repetición simétrica (Figura 8B) es un sistema de patrón diferente, y está diagramado con flechas que reflejan la orientación hacia arriba / hacia abajo y a la derecha / a la izquierda de las figuras. El patrón simétrico es visualmente fuerte sobre las horizontales y verticales. Los bordes exhiben patrones de repetición lineal o unidimensional en color, figura y simetría.

El emparejamiento de la figura con vestido femenino (Figura 7A), con la figura masculina de tocado emplumado (Figura 7B), sobre las mismas diagonales, parece ser significativo ( $F$ - gura 8A). El emparejado está reforzado por las elaboradas diademas que llevan. Las diademas reales se hicieron con hojas de oro martillado, y se les considera como adornos de alto estatus (Sawyer 1960). La pareja de figuras masculino/ femenina viste una variedad particularmente rara de diadema, que es doble (Figura 7A, B). Este detalle sugiere no sólo la relación de las figuras, sino posiblemente su alto rango. La figura masculina también usa una nariguera, que es otro tipo de ornamento de oro encontrado en algunos fardos (Tello y Mejía 1979: Figura 125). La figura con vestido usa pares de alfileres, los que pudieron comunicar un alto rango.

La importancia de la diadema está sugerida por las figuras en parejas que aparecen en varios fragmentos bordados que carecen de procedencia. Las figuras que llevan vestidos femeninos se muestran con parejas masculinas. En un caso, las diademas que llevan aparecen conectadas (Figura 9A) y, en ambos, la pareja agarra los

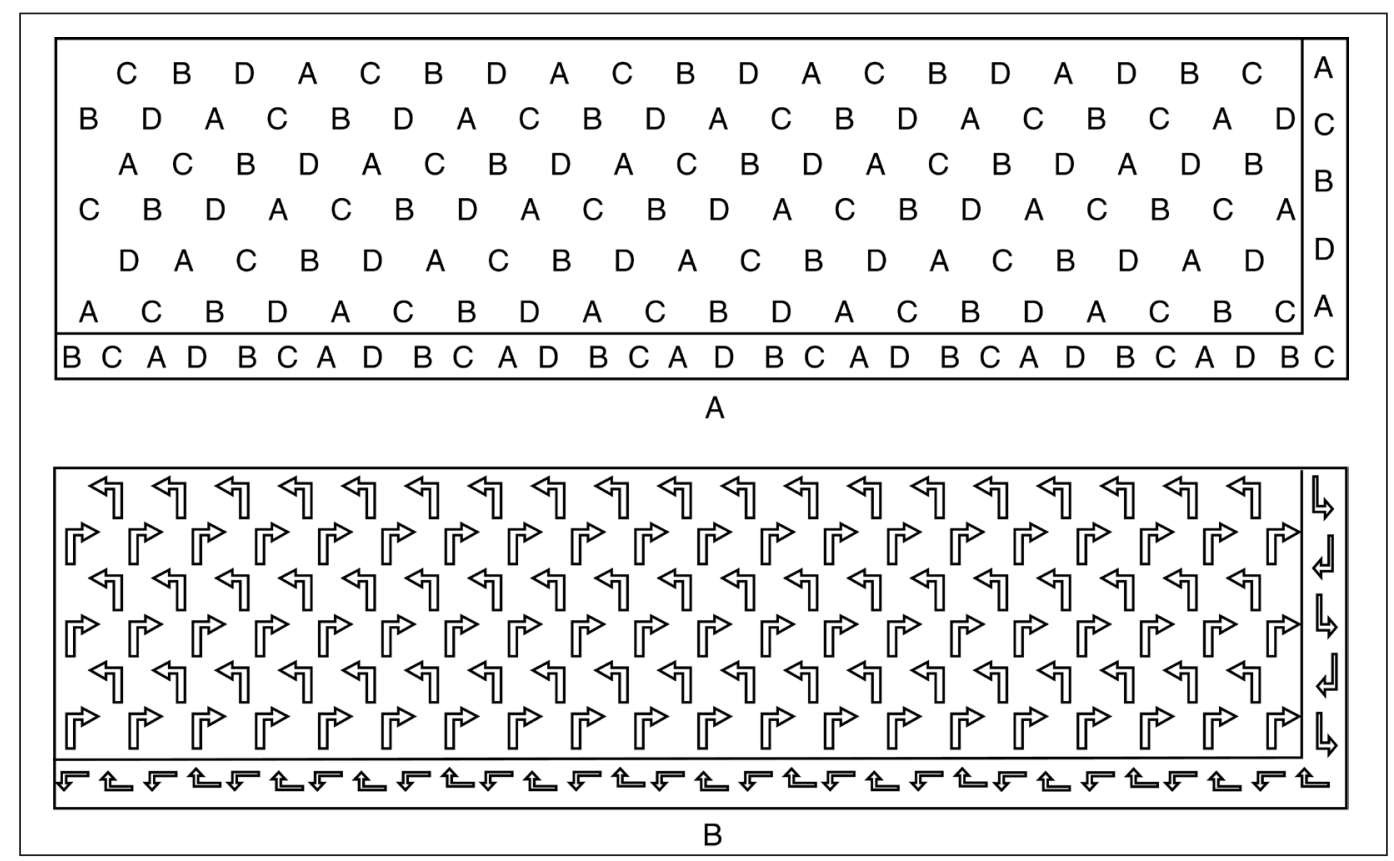

Figura 8. Cuatro figuras (Figura 7A-D) se repiten en un patrón regular sobre el campo y el borde de la falda negra. A. Cuando las repeticiones de las figuras y el color coinciden, son visualmente notables sobre las diagonales que corren de arriba a la izquierda hacia abajo a la derecha. B. Los patrones de simetría son visualmente notables sobre las verticales y horizontales. 
extremos de la misma diadema (Figura 9A, B). La atención sobre la diadema sugiere que es un adorno particularmente significativo, y que las figuras de hombres y mujeres que la llevan comparten un alto estatus como pareja.

Tres de las cuatro figuras de la falda bordada (Figura 7A-C) usan otro tipo de ornamento que también puede indicar estatus. Sus rostros están flanqueados por una cadena de círculos que probablemente representan discos cortados de hojas de oro martillado que fueron cosidos sobre bandas de tela. Tales discos estuvieron entre los artículos de oro en-

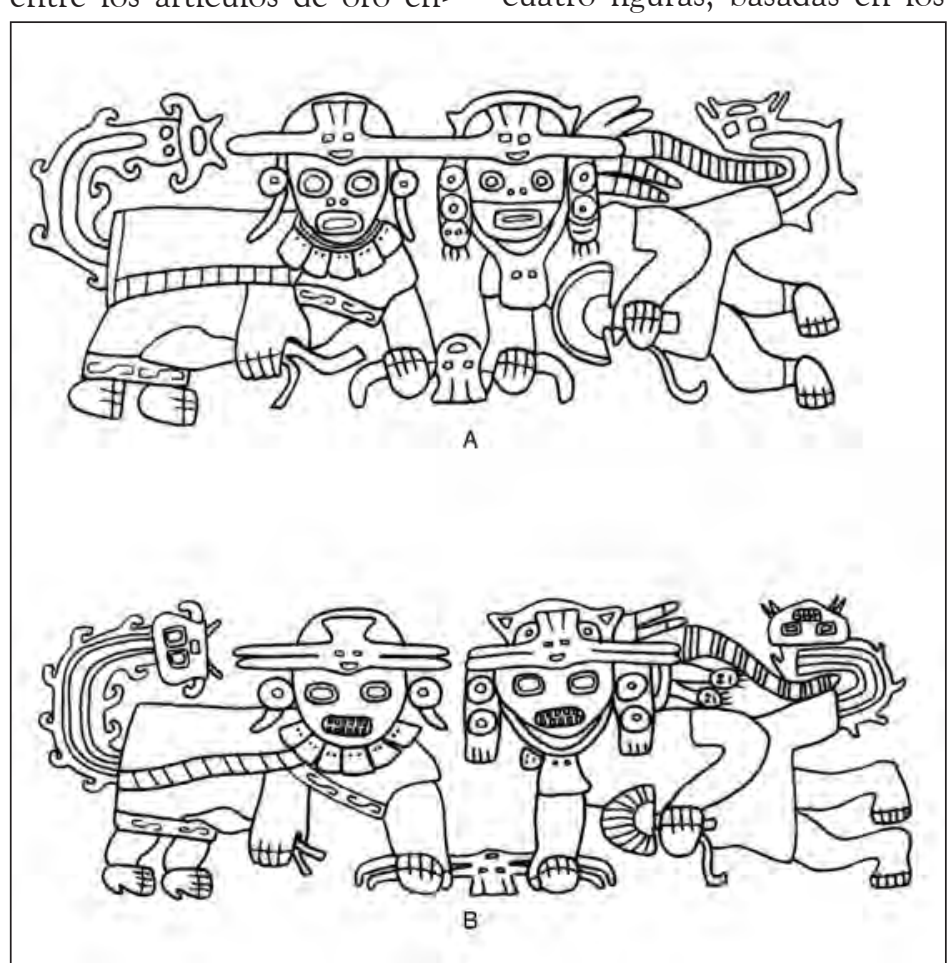

Figura 9. Parejas de mujeres (al lado izquierdo) y hombres (al lado derecho), identificables por sus prendas, sostienen diademas por los extremos. A. TM 91.216 y AS Inv. \#42. B. WCM 35.32.132.

contrados en los fardos (Tello y Mejía 1979: Figura 124). Si los discos también fueron emblemas de estatus, entonces, sobre la base de los ornamentos de oro que llevan, se puede sugerir una jerarquía para las cuatro figuras de la falda. La figura que no lleva discos ni diadema está en la base de esa jerarquía (Figura 7D), lo que podría sugerir que es el más joven o menos maduro. Esta figura lleva un adorno inusual en su turbante que, hasta el momento, no tiene correspondencia con los objetos arqueológicos recuperados en el sitio.

Las relaciones entre las cuatro figuras, basadas en los

\section{sin dicu pareja. Solo una de las figuras} menores lleva discos a la altura de las orejas (Figura 7C). El número de adornos de oro llevados por las figuras sugiere una jerarquía entre ellas. Las prendas indican una oposición de género entre la pareja masculino/femenina, pero el ornamento frontal que llevan sugiere igualdad de rango.

Las relaciones entre las cuatro figuras recuerdan a las prácticas y relaciones sociales generalizadas en el periodo Inka, tanto en el ámbito social cuanto en el ámbito mítico. En el período Inka, las prendas y los adornos, incluyendo sus colores y los materiales con los que fueron hechos, estaban rigurosamente controlados. Las diferencias en materiales, dise- 
ños y colores expresaron rangos, privilegios y roles sociales entre los vivos y los difuntos (Cobo 1979: 244-247). No solo los humanos, sino también los ídolos y las huacas, tales como las rocas y los cuerpos momificados de los Inkas, fueron cuidadosamente adornados con prendas apropiadas (Cobo 1990: 35-43; 108). Los detalles de los trajes observables en los bordados sugieren continuidad con las prácticas de los Inkas en el uso de los tejidos y adornos para expresar rango, privilegio o roles sociales. Los artefactos Inka muestran un patrón enfático que los Ascher han denominado "insistencia Inka" (Ascher y Ascher 1981: 37-57) Los bordados muestran un énfasis igualmente insistente sobre las parejas, parejas de pares, oposiciones, jerarquías y secuencias (Figura 8A, B).

Las tres figuras masculinas de la falda también aparecen en otras prendas bordadas, pero solas, como la única figura que se repite. La figura masculina que lleva el tocado emplumado (Figura 7B) aparece en un manto, una esclavina $\mathrm{y}$ en fragmentos de un turbante ${ }^{15}$. Estas piezas probablemente fueron parte de un juego de prendas, porque todas ellas tienen la misma tela base verde claro y un patrón de color de cuatro partes. Una variante de la figura que usa la misma ropa y porta las mismas cosas en sus manos, pero que tiene un tocado de plumas más pequeño y menos adornos de oro, se repite sobre un manto completo del fardo 18 (18-2, MNAAH RT 1484, de Lavalle y Lang 1977: 52-53).

La segunda figura masculina (Figura 7C) viste una túnica corta con mangas con flecos, un llauto con penacho, y lleva una porra corta y una vara de la cual cuelgan cabezas cortadas. Aunque no hay una wara o falda representada, las mangas con flecos en la túnica son características de las prendas masculinas en este periodo (Rowe 1991: Figuras 12, 13 y 19). La misma figura se repite sobre un manto completo (AMNH 41.0/1500, Stafford 1941: Plate IX).

La figura masculina que lleva un turbante envolvente (Figura 7D) viste una túnica y una falda con flecos. Lleva un bastón de mando y una lanza en sus manos, y exhibe pintura facial distintiva. Una figura similar, que usa una wara en vez de una falda, se repite en un manto (WCM 35.32.208, Paul 1979: 34-35 y Plate 15). La figura tiene un objeto concéntrico a un lado de su cabeza, cuyo significado aún no es claro.

Como se ha indicado arriba y en la nota 13, las cuatro figuras representadas en la falda aparecen como las figuras únicas que se repiten sobre otros tejidos bordados. Mientras los atributos principales, tales como los objetos llevados en las manos y la posición de los brazos concuerdan entre las figuras, hay pequeñas diferencias: el tamaño de los tocados de plumas, el número de ornamentos de oro, la longitud de las prendas, o la sustitución de una wara por una falda. Las figuras no parecen ser tipos de figuras completamente estáticos, y las diferencias pueden señalar modulaciones en el significado, dentro de un código gráfico. La edad, el estatus o los roles sociales son ejemplos del tipo de información que pudo ser indicado por los sutiles tipos de diferencias que se acaban de notar. En un estudio aparte, que trazó la transformación de figuras masculinas en seres zoomorfos, sobre otros bordados de Wari Kayan (Frame 2001), sostuve que las primeras etapas de la secuencia de transformación fueron expresadas a través de adiciones o modificaciones en las prendas y adornos, así como en la longitud del cabello y la postura. Concluí que la falda corresponde a una primera etapa en la secuencia de transformación, antes que la wara, y que la adquisición de adornos más elaborados corresponde a las fases finales. El continuo de etapas entre figuras

15 El manto (MdAL 002, gr. IV, t. 2.1, Mason 1961: 27; Bákula 1992: 56), la esclavina (SM 4.34 1259T, Lumbreras 1976: Figura 102, abajo a la izquierda) y los fragmentos de turbante (SM 659; CMDT 8034 en Solanilla 1999: 30-31; PMH 15-41-30/86901) están dispersos en diferentes colecciones. 
relacionadas se interpreta como etapas de maduración en un ciclo de crecimiento mítico.

\section{El Manto Blanco}

La interrelación de las cuatro figuras de la falda está reforzada y detallada en el manto blanco, donde se muestra un total de ocho figuras diferentes (Figura 10A-H). Las cuatro figuras que aparecen en la falda están presentes (Figura 10A, B, E, F) junto con otras cuatro figuras adicionales (Figura 10C, D, G, H). Tres de las cuatro figuras adicionales visten una túnica corta o poncho con una wara o falda y, sobre la base de estas prendas, pueden ser identificadas como varones.

La cuarta figura adicional (Figura 10D) viste una prenda inusual: una túnica larga con un panel tipo cola a un lado. Este puede ser un tipo raro de prenda masculina. El panel tipo cola en la túnica es un rasgo de las túnicas más cortas vestidas por otras figuras masculinas (Figura 7B, 9A, B y 10B). Los rostros que cuelgan bajo el dobladillo de la túnica larga de la figura muy po- siblemente representan los adornos tejidos con aguja de los extremos de las tiras de las waras. Esta figura puede ser comparada con otras figuras masculinas que también usan un collar con un solo pendiente de concha (Figura 9A, B y 10B), o que usan una nariguera (Figura $7 \mathrm{~B}$ y 10B). La correspondencia entre los adornos de esta figura y aquellos usados por otras figuras masculinas sugiere que esta también es una figura masculina, y que la prenda representada es una versión más larga de la túnica con panel tipo cola.

La mitad de las figuras del manto blanco llevan una diadema doble (Figura 10A-D), y la repetición de estas figuras, que sigue un mismo patrón, nuevamente sugiere la importancia del ornamento. El patrón es un vehículo que tiene el potencial de comunicar, y en el manto blanco están presentes varios niveles de patrones. Se observan patrones individuales para la figura, el color y la simetría (Figura 11A-C).

Se describirán primero los patrones lineales de los bordes en forma de C, sobre los cuales

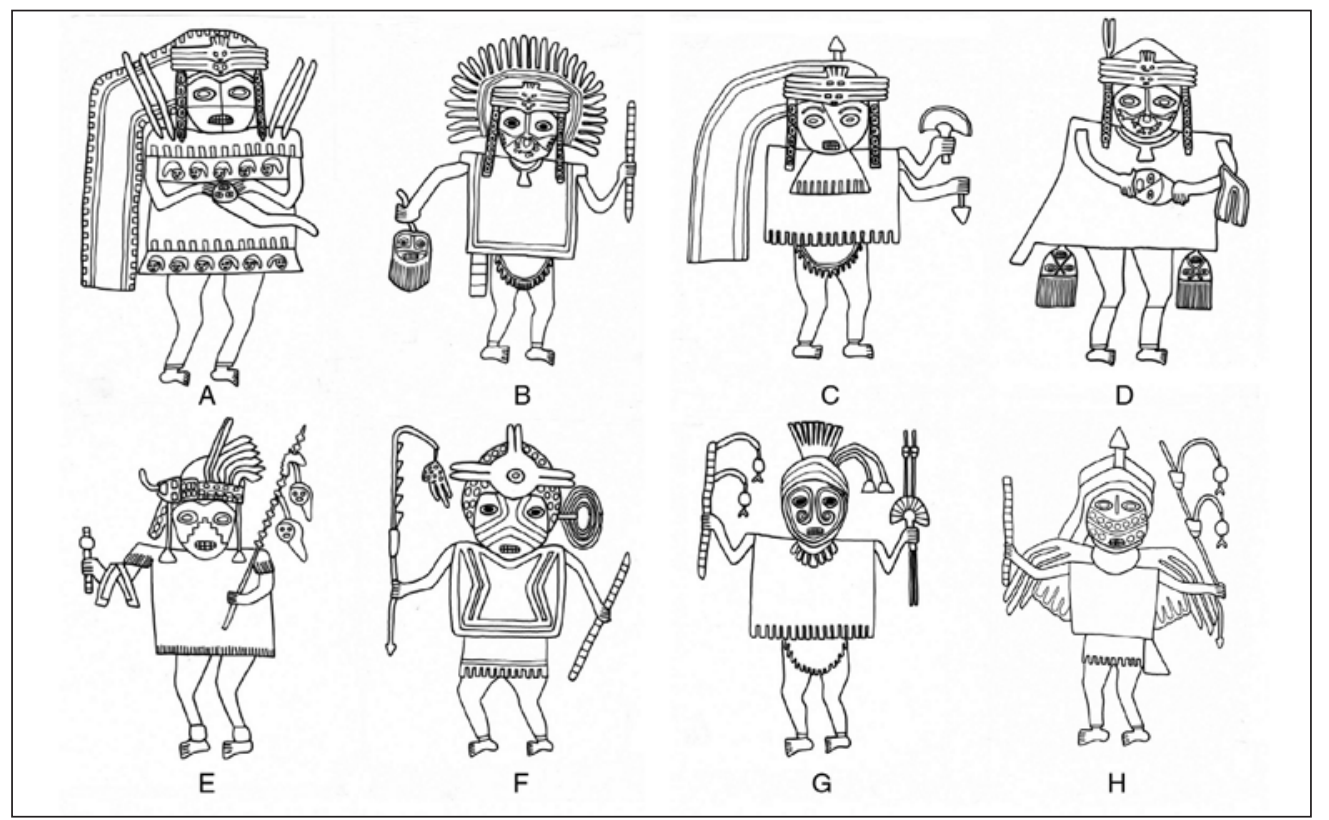

Figura 10. Ocho figuras se repiten sobre el campo y los bordes de un manto bordado de color blanco (SM 4.34 1260). Cuatro figuras (A-D) llevan diademas, y cuatro (E-H) no. 
se repiten 36 figuras. Las ocho figuras del manto blanco se repiten en una secuencia regular sobre los bordes largos, con excepciones menores en dos esquinas (Figura 11A). La secuencia completa de ocho figuras se repite regularmente cuatro veces, pero las cuatro figuras sobrantes no siguen la secuencia. Las figuras que llevan diademas $(A B C D)$ se alternan con las que no las llevan (EFGH), aún en las esquinas de los bordes donde no se sigue la secuencia de ocho figuras. Las figuras en los bordes están coloreadas (en la piel y los vestidos) en tres maneras diferentes (Figura 11B), y los bloques de color se repiten regularmente en una secuencia de tres partes (567) que es completamente regular. Las figuras se alternan mirando hacia la izquierda y a la derecha (Figura 11C) a lo largo de un sendero que rodea el manto, en el sentido de las agujas del reloj, y concuerda con el patrón de simetría más recurrente de los bordes bordados. He sostenido en otro lugar (Frame 2004a) que la alternancia de izquierda a derecha en las figuras de los bordes, denominada simetría "deslizada", corresponde con la locomoción de izquierda a derecha de las figuras que son típicamente caminantes, ya sean bípedos o cuadrúpedos. En los bordes del manto blanco, las secuencias ordinales de ocho, tres y dos están presentes simultáneamente en la alternancia de figuras, colores y orientación de las figuras.

Los niveles de los patrones en el campo del manto son más complejos. Las figuras del campo del manto se organizan en las filas y columnas de un ajedrezado, pero las figuras no se repiten en una secuencia regular sobre el campo. Hay, sin embargo, un patrón sutil sobre las diagonales que corren a través del campo ajedrezado desde arriba a la derecha hacia abajo a la izquierda (Figura 11A). Las cuatro figuras grandes que llevan diademas (Figura 10A-D, Figura 11A: A-D) aparecen sobre diagonales alternas, y las cuatro figuras levemente más pequeñas que no llevan diademas (Figura 10E-H, Figura 11A: E-
H) aparecen en las diagonales intermedias. La segregación de las ocho figuras en dos grupos de cuatro, sobre diagonales separadas, refuerza el patrón notado entre las cuatro figuras de la falda. Ellas están segregadas por el mismo criterio de la diadema, aunque en la falda las diagonales corren desde arriba a la izquierda hacia abajo a la derecha. Es interesante notar que los grupos segregados sobre los campos del manto y la falda están integrados por una alternancia lineal entre los grupos sobre los bordes, que incluye las esquinas del manto. El patrón del campo en la falda y el manto sugiere la segregación de las figuras en dos grupos, mientras el patrón del borde sugiere la integración de los dos grupos en uno total, mayor, a través de la simple alternancia de figuras que pertenecen a grupos diferentes.

Las ocho figuras del manto no se repiten el mismo número de veces sobre el campo y los bordes del manto (Figura 11A), y esta desigualdad parece ser significativa. Entre las figuras mayores que llevan diadema, el varón que usa el tocado de plumas (Figura 11A: B, también Figura 10B) es de lejos el más recurrente: se repite dieciséis veces en el campo y seis veces en el borde. Él también usa tres tipos de adornos de oro. La figura femenina que usa vestido (Figura 11A: A, también Figura 10A) y la figura masculina que viste túnica, wara y turbante largo (Figura 11A: C, también Figura 10C), se repiten diez veces en el campo y cuatro veces en el borde. La figura, supuestamente un varón, que viste la túnica larga (Figura 11A: D, también Figura 10D) se repite solamente seis veces en el campo y cuatro veces en el borde. Esta figura es rara, posiblemente única, en la imaginería bordada y no ha sido ubicada en otros tejidos. No obstante, él usa tres tipos de adornos de oro, lo que sugiere que de alguna manera era un semejante a la figura B. La gran diferencia entre las 22 repeticiones de la figura B y las diez repeticiones de la figura $\mathrm{D}$ parece indicar otro 


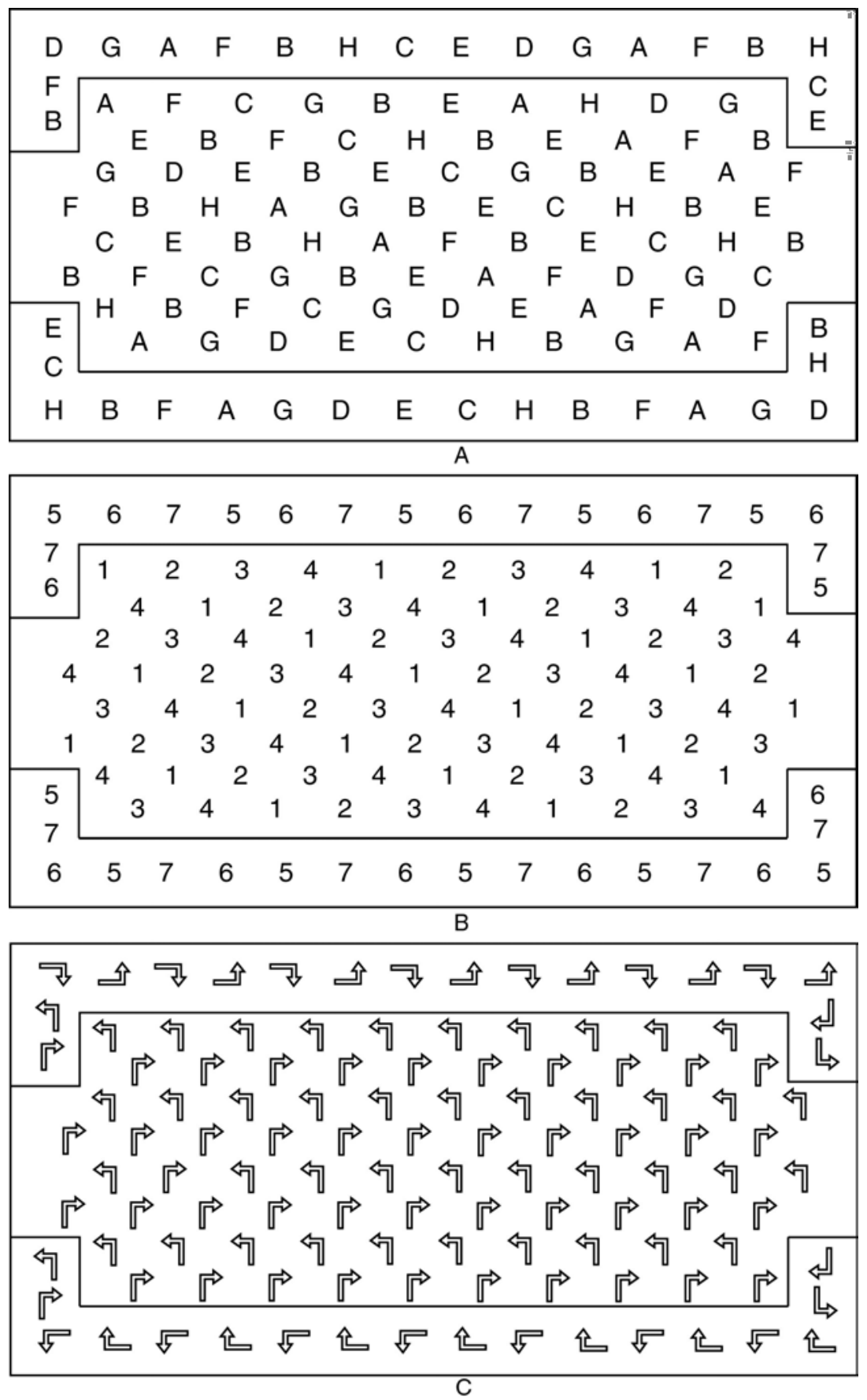

Figura 11. El manto blanco (SM 4.34 1260) exhibe varios niveles de patrones. A. Repetición de 8 figuras: aquellas que llevan diademas $(\mathrm{ABCD})$ están dispuestas sobre diagonales diferentes en el campo del manto, pero se alternan en el borde. B. Cuatro bloques de color se alternan sobre las diagonales en el campo (31 y 24), y tres bloques de color (567) se alternan sobre los bordes. C. Los patrones de simetría están basados en las dos orientaciones de las figuras, tanto en el del campo cuanto en el del borde. 
tipo de jerarquía, donde la figura $B$ es superior a la figura $\mathrm{D}$.

Las dos jerarquías -el número de veces que una figura se repite en el manto y el número de adornos de oro llevados por una figura- no se refuerzan una a la otra, aunque ambas parecen ser significativas. Las figuras menores sin ornamentos de oro (Figura 11A: E, F, G, H, también Figuras $10 \mathrm{E}, \mathrm{F}, \mathrm{G}, \mathrm{H})$ se repiten más veces que algunas de las figuras que llevan ornamentos de oro. En el plano del manto (Figura 11A), la figura E se repite diecisiete veces (trece veces en el campo y cuatro veces en el borde); la figura $\mathrm{F}$, dieciséis veces (once veces en el campo y cinco veces en el borde); la figura $G$, catorce veces (diez veces en el campo y cuatro veces en el borde) y la figura $\mathrm{H}$, trece veces (ocho veces en el campo y cinco veces en el borde). El número de repeticiones puede sugerir un ordenamiento jerárquico entre las figuras que no lucen diademas de oro, diferente de la jerarquía de las figuras que sí las tienen. Las múltiples jerarquías pueden expresar aspectos diferentes del estatus, rol o privilegio dentro de $-\mathrm{o}$ entre- los dos grupos de figuras.

La figura que usa el tocado emplumado grande (Figura 11A: B, Figura 10B) está en la cima de ambas jerarquías, lo que sugiere su alto estatus y posiblemente una posición de autoridad. La figura femenina con vestido (Figura 11A: A, Figura 10A) se empareja o se agrupa con él en la falda y el manto, en las repeticiones en diagonal sobre los campos de las prendas. Este emparejamiento podría sugerir una relación de esposa/consorte. La presencia de una pareja masculino/femenina, más dos figuras masculinas adicionales que también llevan diademas, podría indicar un linaje o grupo familiar de alto rango. Si las cuatro figuras grandes en el manto componen un linaje o grupo de parentesco de alto rango, real o mítico, las jerarquías sugieren que dos de las figuras mascu- linas (Figura 11A: C, D; Figura 10C, D) son inferiores a la figura masculina central (Figura 11A: B, Figura 10B) en algún aspecto.

Una hipótesis que encaja con las jerarquías observadas es que los varones menos recurrentes son el hijo (aparentemente heredero) y el padre (autoridad anterior) de la figura masculina central (Figura 11A: B) que lleva el tocado emplumado grande. La figura que lleva los tres tipos de ornamentos de oro, pero que aparece menos veces (Figura 11A: D, Figura 10D), podría haber logrado el derecho de llevar los ornamentos a través de roles sociopolíticos previos, pero el apogeo de su autoridad ya habría pasado. La otra figura (Figura 11A: C, Figura 10C), cuya autoridad (como heredero) podría ser solo potencial, lleva menos ornamentos de oro y se repite tantas veces como la figura femenina (Figura 11A: A, Figura 10A). Aunque esta hipótesis no puede ser probada o demostrada fácilmente, las relaciones jerárquicas entre las cuatro figuras que llevan diademas y otros adornos de oro son consistentes con estructuras de linaje o sociopolíticas de este tipo.

Las cuatro figuras mayores que lucen diademas exhiben un patrón inusual, pero regular, de repetición sobre las diagonales que se alternan en el campo del manto, aun cuando las figuras se repitan un número diferente de veces. Al usar las letras $A B C D$ para identificar a las figuras (Figura $10 \mathrm{~A}, \mathrm{~B}, \mathrm{C}, \mathrm{D})$, el patrón de repetición sobre las diagonales que se alternan, que corre desde arriba a la derecha hacia abajo a la izquierda, es BCBA, con D como sustituto libre en la secuencia (Figura 11A). Este patrón es bastante difícil de ver, parcialmente porque la repetición de las cuatro figuras menores (Figura 11A: E, F, G, H; Figura 10E, F, G, H) sobre las diagonales que se alternan es menos regular ${ }^{16}$.

La segregación de las figuras menores sin

${ }_{16}$ El patrón predominante en las diagonales alternas, para las figuras menores, es EGEF con $\mathrm{H}$ como sustituto libre. Sin embargo, hay 7 desviaciones de este patrón entre las 42 figuras (Figura 11A), un número bastante grande como para que este patrón sea significativo. 
diademas sobre diagonales diferentes de aquellas de las figuras mayores con diademas seguramente es significativa, especialmente porque la misma segregación aparece en la falda y en el manto. La segregación indica que las ocho figuras están divididas en dos categorías. Si las figuras mayores (Figura 10A-D) corresponden a un linaje o grupo de parentesco de alto rango, entonces las figuras menores sin adornos de oro podrían corresponder a un grupo de menor prestigio. En el dominio social, podrían equipararse con una mitad o clase más baja, dependiendo de cuál fuera el sistema de organización social. En el dominio mítico, ellos podrían corresponder a los asistentes de los ancestros o dioses. Una de las figuras masculinas menores (Figura 10H) tiene los atributos de un cóndor, considerado a menudo como mensajero de los dioses en el folklore andino.

La figura $10 \mathrm{H}$ tiene alas, cola y collar de cóndor, pero también viste una túnica sin mangas, una falda con flecos y un turbante envolvente. Lleva un bastón de mando y una vara con una punta aguzada y frutos colgantes. Tiene un cuchillo metido en el turbante. Las figuras que difieren de esta-solamente por el hecho que visten una wara en vez de una falda- aparecen por lo menos en tres mantos y una wara ${ }^{17}$.

Otra de las figuras menores (Figura 10G) del grupo de ocho en el manto blanco aparece con mayor variación sobre otros tejidos y fragmentos. El penacho y los brotes que cuelgan del tocado, así como la túnica simple y la wara, se ven en varios fragmentos (MMA 33.149.26; TBM 34.561). Sin embargo, figuras como esta sostienen diversos objetos en sus manos. Otra figura sobre un manto completo del fardo 18 (18-2, MNAAH RT 1484, De Lavalle y Lang 1977: 52-53) tiene el tocado de la figura 10G, pero viste las ropas y sostiene los mismos objetos que la figura 10B.

La variabilidad en la figura $10 \mathrm{G}$ contribuye a la impresión de que las figuras no son tipos estáticos, aunque algunas aparezcan sobre varios tejidos virtualmente en la misma forma. A veces ellas aparecen con sutiles variaciones que sugieren modulaciones en el significado. Si las prendas y adornos son marcadores de rango, estatus o roles en los bordados, entonces las variaciones en las figuras pueden ilustrar etapas en la adquisición de esos marcadores. Tal como los emblemas y las medallas militares, los matices en la ropa y el adorno en las figuras similares pudieron comunicar información específica.

El manto blanco, con su colección de ocho figuras (Figura 10A-H) y sistemas de patrones superpuestos (Figura 11A-C), es un documento extraordinario que revela más que la mayoría de los bordados Paracas Necrópolis. Provee de un contexto iconográfico para las figuras que aparecen individualmente en otros tejidos, incluso mujeres. También proporciona un ejemplo de cómo el patrón puede ser articulado con la iconografía en la comunicación visual.

\section{Conclusiones}

La descripción de las prendas y adornos femeninos representados en los tejidos del fardo 382 (Figura 1A-C) aclara las distinciones de género entre las figuras bordadas. Por contraste, las prendas masculinas, así como los adornos llevados por hombres y mujeres, también se hacen más evidentes. El rasgo más consistente para identificar un vestido femenino, y el género de la figura que lo viste, es el borde horizontal que atraviesa el dobladillo de la prenda.

La presencia de alfileres sobre los hombros y la representación de un segundo borde horizontal sobre el corpiño también son rasgos de la representación de los vestidos femeninos, pero no siempre están presentes. Aparentemente, algunos vestidos fueron cosidos sobre los hombros,

17 Los mantos con la figura del cóndor son: 290-14, MNAAH RT 3335 (Taullard 1949: Figura 28 y Tello y Mejía 1979: Figura 107); WCM 35.32.209 (Paul 1979: 37 y Plate 19); y TM 91.337 (Bird 1954: Pls. III, LXI y LXII). La wara con la figura de cóndor es BMFA 21.2561 (Stone-Miller 1992: Figura 89). 
tal como los exhumados en Cahuachi (Frame 2005). Aquí se han ilustrado ejemplos de representaciones de vestidos Nasca sin tupus en los hombros (Figuras 5A-C; 9A, B). Las mujeres representadas en la figura 9 A y $B$ llevan un collar característico hecho con varios pendientes de concha, en contraste con los hombres, que llevan un único pendiente de concha en una cuerda. Este adorno es una clave útil para identificar representaciones de mujeres que usan vestidos sin alfileres sobre los hombros entre los bordados Paracas Necrópolis ${ }^{18}$. El contexto iconográfico de mujeres que visten vestidos sin alfileres sobre los hombros puede ser explorado en varios tejidos de los fardos Necrópolis que muestran figuras múltiples, tales como 290-45 (RT 5906) y 253-65 (RT 1027). Como estos dos tejidos parecen estar más estrechamente relacionados con el estilo Nasca, pueden revelar relaciones diferentes entre las figuras que aquellas del manto blanco.

$\mathrm{Al}$ examinar las interrelaciones entre las figuras de distinto género que están agrupadas en el mismo tejido, se revelan categorías fundamentales e interrelaciones jerárquicas entre ellas. La estructura de las interrelaciones provee una base para sugerir que los vestidos y adornos de las figuras reflejan la estructura de las relaciones sociopolíticas o míticas.

Algunos niveles de los patrones atraviesan las categorías, jerarquías y los emparejamientos complementarios entre las figuras, y son particularmente evidentes en el manto blanco. Todas las figuras están reunidas en un todo a través de la repetición cíclica de bloques de color. El campo del manto exhibe un patrón clásico basado en cuatro maneras diferentes de colorear las figuras (señalado como 1234, Figura 11B). El efecto visual es más fuerte sobre las líneas diagonales que corren desde arriba a la derecha y hacia abajo a la izquierda del campo ajedrezado. Cada diagonal tiene un patrón de dos colores, 1313 ó 2424 , y los dos patrones se alternan el uno con el otro. Este es un patrón binario doble, donde los colores en pares se alternan sobre diagonales en pares ${ }^{19}$. Este es el patrón de color más recurrente en los tejidos bordados, y también en los tejidos de estilos posteriores. La persistencia de este patrón de cuatro colores durante un lapso de 1500 años sugiere que pudo codificar un aspecto particularmente durable de la organización cultural: el todo de cuatro partes compuesto por dos grupos de rangos pares (Frame 2004b; 2007a).

Un patrón de color aparte se utiliza para las figuras del borde del manto blanco, donde los bloques de color están construidos por combinaciones diferentes de color en la pierna y en la túnica/vestido. Los bordes tienen una secuencia de color de tres partes (señalada como 567, Figura 11B). Las secuencias lineales de duraciones diferentes, como aquellas de los bordes y diagonales del campo, tienen el potencial de incluir conceptos ordinales o cíclicos. Por ejemplo, los esquemas rotativos o las ideas de tiempo cíclico también podrían estar reflejados en las secuencias de color de tres y cuatro partes.

Las dimensiones del color, de la simetría y del patrón de las figuras en el manto blanco

18 Las representaciones de mujeres que usan vestidos que no tienen alfileres sobre los hombros, o con borde a través del pecho, aparecen en ejemplares como 38-15 (MNAAH RT 1410), 38-39b (RT 2555), 38-49 (MNAAH RT 3043), 253-7 (RT 2753), 258-6 (RT 101), 262-15 (RT 2541), 319-57 (MNAAH RT 1651), 319-93 (RT 2455), AIC 1970.293, y TM 91.215 (Bird 1954: Plate LXXXI).

19 Un patrón binario doble de este tipo también puede ser expresado en una cuerda de cuatro colores. Una cuerda hecha con dos cuerdas bicolores, replegadas, muestra la misma alternancia de color sobre las diagonales estructurales de la cuerda. Sugiero que varios tipos de patrones de color de los bordados pueden haber sido conceptualizados en términos de las estructuras de cuerdas. Las imágenes de esta estructura de cuerda (Frame 1991: Figura 4.28), y otras, están representadas en los llautos de entrelazado oblicuo de los fardos Paracas Necrópolis. 
superan a aquellas de la mayoría de las prendas bordadas ${ }^{20}$. En la densidad de los números, secuencias y combinaciones de los patrones, reside un potencial para la inclusión matemática de fórmulas y relaciones. Si tengo razón en pensar que las fórmulas para la orquestación de las actividades de la población en el tiempo y en el espacio pueden ser incluidas en la matriz de los patrones (Frame 2007a), entonces los patrones generales (Figura 11A-C) pueden haberse aplicado a la formación social como un todo. La iconografía parece comunicar distinciones de género, categorías de estatus y, posiblemente, relaciones de linaje entre las figuras específicas representadas. Algunos aspectos del patrón reiteran categorías y jerarquías en la iconografía, y otros aspectos son más incluyentes. Claramente, las mujeres tenían un lugar en la formación social y en el mito, y ahora podemos identificar representaciones de ellas en los bordados, por las prendas que visten. Aunque las representaciones de mujeres son mucho menos numerosas que las representaciones de hombres, sus adornos de oro sugieren que también tuvieron un alto rango.

Las interrelaciones en el mundo mítico lógicamente pudieron reflejar las relaciones sociales entre los vivos, y sirvieron para aumentar y promover la continuación de la formación social. Los regímenes, desde las pequeñas jefaturas hasta los estados complejos, usan el arte, el mito y la religión para validar su existencia. Aunque se sabe poco sobre la organización social en la Costa Sur de hace casi dos milenios, podemos estar en una mejor posición para hacer hipótesis sobre la formación y las relaciones sociales, reales y míticas, a través del análisis cuidadoso de las interrelaciones entre las figuras y de los patrones de repetición sobre los tejidos bordados.

\section{Agradecimientos}

Deseo agradecer a Javier Alcalde, Wilbert Salas y Lourdes Chocano por su asistencia en el Archivo Tello del Museo de Arqueología y Antropología del Centro Cultural de San Marcos en el año 2004. También, agradecer al personal, pasado y presente, del Museo Nacional de Arqueología, Antropología e Historia del Perú, por su asistencia durante el estudio de los bordados, en particular a María Ysabel Medina, Carmen Thays, Edouard Versteylen, Carlos Del Águila y Carmen Arellano. Mis agradecimientos a las colegas Isabel Iriarte y Delia Aponte, quienes amablemente brindaron comentarios a una versión anterior de este artículo, y a Pedro Novoa por la traducción. Estoy particularmente agradecida con la Selz Foundation por haber proveído los fondos para mis viajes en varias oportunidades, lo que me ha permitido realizar investigaciones en las diferentes colecciones peruanas.

\section{Abreviaturas USADAS}

AS Abegg-Stiftung, Riggisberg, Switzerland AIC Art Institute of Chicago

AMNH American Museum of Natural History, New York

CDMT Centre de Documentación i Museu Textil, Terrassa, España

EMB Ethnologisches Museum, Berlin

MMA Metropolitan Museum of Art

SM Museo de Arqueología y Antropología de la Universidad Nacional Mayor de San Marcos

MdAL Museo de Arte de Lima MFAB Museum of Fine Arts, Boston MNAAH Museo Nacional de Arqueología, Antropología e Historia del Perú PMH Peabody Museum, Harvard TM Textile Museum, Washington TBM The Brooklyn Museum WCM World Cultures Museum, Goteborg

20 Véase Paul (1997 y 2004) para los patrones de color y simetría. Entre 1987 y 1993 reuní y analicé los datos de los patrones en los bordados (Frame 1989; 1991), que Paul incorporó libremente en sus publicaciones. 


\section{BibliografíA}

Aponte, Delia

s.f. La vestimenta femenina de Paracas Necrópolis. Manuscrito en posesión de la autora, citado con permiso.

Ascher, Marcia y Robert Ascher

1981 Code of the Quipu: A Study in Media, Mathematics, and Culture. Ann Arbor: The University of Michigan Press.

Bákula, Cecilia (ed.)

1992 Perú: Presencia Milenaria, Exposición Universal de Sevilla 1992. Catálogo del Pabellón del Perú. Arequipa: Cuzzi y Cía., S. A.

Bennett, Wendell C.

1938 If You Died in Old Peru. Natural History 41(2): 119-125. New York: American Museum of Natural History.

Betanzos, Juan de

1996 Narrative of the Incas. Translated and edited by Roland Hamilton and Dana Buchanan from the Palma de Mallorca manuscript [Suma y narración de los incas, 1576]. Austin: University of Texas Press.

Bird, Junius B.

1954 Paracas Fabrics and Nazca Needlework: 3rd century B.C.-3rd century A.D. Technical Analysis by Louisa Bellinger. Catalogue Raisonné. Washington: The Textile Museum.

Carrión, Rebeca

1931 La Indumentaria en la antigua cultura de Paracas. Wira Kocha (Lima), vol. I, No. 1: 37-86.

Cobo, Bernabé

1979 History of the Inca Empire: An account of the Indians' customs and their origin together with a treatise on Inca legends, history, and social institutions [1653]. Translated and edited by Roland Hamilton. Foreword by John Rowe. Austin: University of Texas Press.

1990 Inka Religion and Customs [1653]. Translated and edited by Roland Hamilton. Foreword by John Rowe. Austin: University of Texas Press.

Daggett, Richard E.
1991 Paracas: Discovery and Controversy. En Paracas, Art and Architecture: Object and Context in South Coastal Peru. Anne Paul, editor, pp. 35-60. Iowa City: University of Iowa Press.

Desrosiers, Sophie

1992 Las técnicas del tejido itienen un sentido? Una propuesta de lectura de los tejidos andinos, y Respuesta. Revista Andina 19, 10 (1): 7-34, 43-46. Cusco: Centro Bartolomé de las Casas.

Dransart, Penélope

1999 Vestirse en los periodos tardíos del centro-sur andino, Actas de la I Jornada sobre Textiles Precolombinos, pp. 12753. Editadas por Victòria Solanilla. Barcelona: Universitat Autònoma de Barcelona.

Dwyer, Edward y Jane Dwyer

1973 The Paracas Cemeteries: Mortuary Patterns in a Peruvian South Coastal Tradition. En Death and the Afterlife in Pre-Columbian America, editado por Elizabeth Benson, pp. 145-161. Dumbarton Oaks, Washington, D.C.

Eisleb, Dieter

1975 Altperuanische Kulturen I. Veröffentlichungen des Museums für Völkerkunde Berlin, n.F. 31. Abteilung Amerikanische Archäologie III. Berlin: Museum für Völkerkunde.

Fester, Gustavo y José Cruellas

1934 Colorantes de Paracas. Revista del Museo Nacional 3(2):154-163.

Frame, Mary

1989 Research-in-progress Report, Orientation and Symmetry: The Structuring of Pattern Repeats in the Paracas Necropolis Embroideries. En Textiles as Primary Sources: Proceedings of the First Symposium of the Textile Society of America, September 1988, pp. 136-138. Co-ordinated by John Vollmer.

1991 Structure, Image, and Abstraction: Paracas Necropolis Headbands as System Templates. En Paracas Art and Architecture: Object and Context in South Coastal Peru, pp. 110-171. Anne Paul, 
editora. Iowa City: University of Iowa Press.

1995 Ancient Peruvian Mantles: 300 B.C. - A.D. 300. Metropolitan Museum of Art, New York.

2001 Blood, Fertility, and Transformation: Interwoven Themes in the Paracas Necropolis Embroideries. En Ritual Sacrifice in Ancient Peru, pp. 55-92. Elizabeth P. Benson y Anita G. Cook, editoras. Austin: University of Texas Press.

2004a Motion Pictures: Symmetry as Animator, Classifier, and Syntax in the Nasca Embroideries of Peru. En Symmetry Comes of Age: The Role of Pattern in Culture, pp. 133-176. Dorothy Washburn y Donald Crowe, editores. Seattle: University of Washington Press.

2004b Tukapu, A Graphic Code of the Inkas. En Tejiendo Sueños en el Cono Sur, Textiles Andinos: Pasado, Presente y Futuro, Actas del simposio ARQ-21, 51을 Congreso Internacional de Americanistas, Santiago, Chile, 14-18 julio de 2003, pp. 236-60. Editadas por Victoria Solanilla. Barcelona: Grup d'Estudis Precolombins.

2005 What the Women were Wearing: A Deposit of Early Nasca Dresses and Shawls from Cahuachi, Peru. Washington: En Textile Museum Journal 2003-2004, vols. 42 y 43: 13-53.

2007a Pathways to the Past: Strategies for Investigating Ancient Andean Textiles. En Recovering the Past: The conservation of archaeological and ethnographic textiles, pp. 1-15. Compilado por Emilia Cortés y Suzanne Thomassen-Krauss. Preprints of the North American Textile Conservation Conference 2005 (Mexico City), vol. 5. McNaughton and Gunn.

2007b Las prendas bordadas de la Necrópolis de Wari Kayan. En Hilos del pasado. El aporte francés al legado Paracas, pp. 65-73. Instituto Nacional de Cultura y Museo Nacional de Arqueología y
Antropología del Perú.

s. f. El estilo silueta: el "otro" estilo color en bloque en los bordados Paracas Necrópolis. Ponencia presentada en la Reunión Anual de la Society for American Archaeology, Vancouver, 26-30 de marzo de 2008.

Iriarte, Isabel

2004 La donación de un fardo Paracas a la Argentina: circunstancias y protagonistas (con Reconstrucción iconográfica y documentación gráfica de Juan López). En: Textiles precolombinos, coleccionismo y pintores modernos. SEPARATA Año IV, № 7 y 8 , octubre 2004. Rosario, Argentina: Centro de Investigaciones del Arte Argentino y Latinoamericano, Universidad Nacional de Rosario.

De Lavalle, José Antonio y Werner Lang (eds.)

1977 Arte Precolombino, primera parte: Arte y Tesoros del Perú. Lima: Banco de Crédito del Perú.

1983 Culturas Precolombinas, Paracas: Arte y Tesoros de Perú. Lima: Banco de Crédito del Perú.

Lumbreras, Luis G.

1976 The Peoples and Cultures of Ancient Peru. Translated by Betty J. Meggers [1974]. Washington: Smithsonian Institution Press.

Martin, Lois

1991 The Paracas Textile, Brochure and Slide Set. Brooklyn: The Brooklyn Museum.

Mason, J. Alden

1961 Introducción al arte textil peruano (Brief Guide to the Peruvian Textiles). Translated by Horacio Vera Portocarrero. Lima: Tipografía Peruana.

O’Neale, Lila

1937 Archaeological Explorations in Peru, Part III: Textiles of the Early Nasca Period. Anthropology, Memoirs, vol. II, no. 3. Field Museum of Natural History, Chicago.

Paul, Anne

1979 Paracas Textiles: Selected from the 
Museum's Collections, Etnologiska Studier 34. Göteborg: Göteborgs Etnografiska Museum.

1990a Paracas Ritual Attire: Symbols of Authority in Ancient Peru. Norman: University of Oklahoma Press.

1990b The Use of Color in Paracas Necropolis Fabrics: What Does It Reveal about the Organization of Dyeing, Designing, and Society? National Geographic Research 6(1): 7-21.

1997 Color Patterns on Paracas Necrópolis Weavings: A Combinatorial Language on Ancient Cloth. Techniques et culture (janvier-juin) 29:113-153. Paris: Editions de la Maison des Sciences de l'Homme.

2004 Symmetry Schemes on Paracas Necropolis Textiles. En Embedded Symmetries: Natural and Cultural, pp. 5880. Dorothy Washburn and Donald Crowe, editors. Albuquerque: University of New Mexico Press.

Paul, Anne y Susan Niles

1984 Identifying Hands at Work on a Paracas Mantle. Textile Museum Journal 23: 5-15. Washington.

Rowe, Ann P.

1991 Nasca Figurines and Costume. Textile Museum Journal 29 and 30: 93-128. Washington.

Sawyer, Alan R.

1960 Paracas Necropolis Headdress and Face Ornaments. Workshop Notes, Paper 21, May. Washington: Textile Museum.

Solanilla, Victòria

1999 Textils Precolombins de Colleccions Publiques Catalanes. Barcelona: Institut d'Estudis Catalans.

Stafford, Cora E.

1941 Paracas Embroideries: A Study of Repeated Patterns. New York: J. J. Augustin Publisher.

Stone-Miller, Rebecca

1992 To Weave for the Sun: Andean Textiles in the Museum of Fine Arts, Boston. Boston: Museum of Fine Arts.
Taullard, Alfredo

1949 Tejidos y Ponchos Indígenas de Sudamérica. Buenos Aires: Editorial Guillermo Kraft Limitada.

Tello, Julio C.

1929 Antiguo Perú: primera época. Comisión organizadora del Segundo Congreso Sudamericano de Turismo. Lima

1959 Paracas: Primera Parte. Lima: Empresa Gráfica Scheuch S.A.

Tello, Julio C. y Toribio Mejía

1979 Paracas II parte: Cavernas y Necrópolis. Publicación antropológica del Archivo Documental Julio C. Tello. Lima: Universidad Nacional Mayor de San Marcos y New York: The Institute of Andean Research.

Ulloa, Liliana

1981 Estilos decorativos y formas textiles de poblaciones agromarítimas en el extremo norte de Chile, Revista Chungará, vol. 8, pp. 109-36. Arica: Universidad del Norte, Dpto. de Antropología.

Yacovleff, Eugenio

1932a La deidad primitiva de los Nasca. Revista del Museo Nacional 1(2):103-161. Lima.

1932b Las falcónidas en el arte y en las creencias de los antiguos Peruanos. Revista del Museo Nacional 1(1): 35-111. Lima.

1933 La Jíquima, raíz comestible extinguida en el Perú. Revista del Museo Nacional 1(1): 49-66. Lima.

Yacovleff, Eugenio y Fortunato L. Herrera

1934 El mundo vegetal de los antiguos peruanos. Revista del Museo Nacional 3(3):241-322. Lima.

Yacovleff, Eugenio y Jorge C. Muelle

1934 Un fardo funerario de Paracas. Revista del Museo Nacional 3(1-2):63-153. Lima. 